Methodology article

\title{
Generation of an external guide sequence library for a reverse genetic screen in Caenorhabditis elegans Qitao Yan ${ }^{\dagger 1}$, Rui Zhao ${ }^{\dagger 1}$, Wenlin Zheng ${ }^{2,3}$, Changxin Yin ${ }^{1}$, Bao Zhang1 and Wenli Ma*1
}

\author{
Address: ${ }^{1}$ Institute of Molecular Biology, Southern Medical University, Guangzhou, 510515, PR China, ${ }^{2}$ Southern China Genomics Research \\ Center, Guangzhou, 510800, PR China and ${ }^{3}$ Gendustry Development Group (GDG), Guangzhou, 510800, PR China \\ Email: Qitao Yan - Yanqitao1979@126.com; Rui Zhao - zhaoruiruizhao@yahoo.com.cn; Wenlin Zheng - gendustry@gmail.com; \\ Changxin Yin - changxin0128@163.com; Bao Zhang - beibei20051005@foxmail.com; Wenli Ma* - mawenli66@126.com \\ * Corresponding author †Equal contributors
}

Published: 20 May 2009

BMC Biotechnology 2009, 9:47 doi:10.1 186/1472-6750-9-47
Received: 17 June 2008

Accepted: 20 May 2009

This article is available from: http://www.biomedcentral.com//472-6750/9/47

(c) 2009 Yan et al; licensee BioMed Central Ltd.

This is an Open Access article distributed under the terms of the Creative Commons Attribution License (http://creativecommons.org/licenses/by/2.0), which permits unrestricted use, distribution, and reproduction in any medium, provided the original work is properly cited.

\begin{abstract}
Background: A method for inhibiting the expression of particular genes using external guide sequences (EGSs) has been developed in bacteria, mammalian cells and maize cells.

Results: To examine whether EGS technology can be used to down-regulate gene expression in Caenorhabditis elegans (C. elegans), we generated EGS-Ngfp-lacZ and EGS-Mtgfp that are targeted against Ngfp-lacZ and Mtgfp mRNA, respectively. These EGSs were introduced, both separately and together, into the $C$. elegans strain PD425I, which contains Ngfp-lacZ and Mtgfp. Consequently, the expression levels of Ngfp-lacZ and Mtgfp were affected by EGS-Ngfp-lacZ and EGS-Mtgfp, respectively. We further generated an EGS library that contains a randomized antisense domain of tRNA-derived EGS ("3/4 EGS"). Examination of the composition of the EGS library showed that there was no obvious bias in the cloning of certain EGSs. A subset of EGSs was randomly chosen for screening in the $C$. elegans strain N2. About $6 \%$ of these EGSs induced abnormal phenotypes such as $\mathrm{PO}$ slow postembryonic growth, P0 larval arrest, P0 larval lethality and P0 sterility. Of these, EGS-35 and EGS-83 caused the greatest phenotype changes, and their target mRNAs were identified as ZK858.7 mRNA and Lin-13 mRNA, respectively.
\end{abstract}

Conclusion: EGS technology can be used to down-regulate gene expression in C. elegans. The EGS library is a research tool for reverse genetic screening in $C$. elegans. These observations are potentially of great importance to further our understanding and use of $C$. elegans genomics.

\section{Background}

RNase P catalyzes the maturation of 5 '-termini of all tRNAs by a single endonucleolytic cleavage of their precursors[1]. This enzyme is found in cells from all three domains of life: the Bacteria, Eukaryote and Archaea [2-5]. One of the unique features of RNase P is its ability to recognize the structures, rather than the sequences, of tRNAs; this allows the enzyme to cleave other substrates with similar structure to the tRNA precursor. Accordingly, any complex of two RNA molecules that resembles a similar tRNA molecule can be recognized and cleaved by RNase P [6-8]. One of the two RNA molecules that resemble the complex is termed the external guide sequence (EGS). In principle, an mRNA sequence can be targeted for RNase $\mathrm{P}$ 
cleavage by hybridization with EGS to direct RNase P to the cleavage site. Subsequent studies have shown that EGS technology can be used to down-regulate gene expression in many organisms, such as bacteria, [9-12] mammalian cells [13-19] and maize cells[20].

Nucleic-acid-based gene-interference strategies, such as anti-sense oligonucleotides, ribozymes, and RNAi, are powerful research tools and promising therapeutic agents for human diseases [21-25]. Each technology has advantages and limitations in terms of targeting efficacy and specificity [26]. Compared with other nucleic-acid-based gene-interference strategies, such as the RNAi approach that induces the cellular RISC RNase to cleave a target mRNA [26,27], targeted cleavage of mRNA by RNase P using an EGS is a unique approach that can be used to inactivate any RNA of known sequence expressed in vivo. Moreover two types of interaction govern the targeting specificity of EGS[3,19]. One is the Watson-Crick basepairing interaction between the anti-sense domain of an EGS and the accessible region of a target mRNA. The other is the interaction between a target mRNA and the other domains of an EGS, which are required for folding of the RNase P-recognizable tertiary structure.

Several EGSs derived from natural tRNA sequences have been shown to be effective in blocking gene expression in bacteria[12,28] and mammalian cells[29]. For example, the "3/4 EGS" resembles three-quarters of the tRNA molecule and consists of two sequence elements: a targeting sequence that is complementary to the accessible region of a target mRNA in which most sequences are inaccessible owing to the secondary or tertiary structures of the RNA and or the binding of proteins; and a RNase-P-recognizing sequence that is a portion of the tRNA sequence and required for interacting with RNase P[8]. It has been demonstrated that the "3/4 EGS" effectively and specifically induces target mRNA cleavage by eukaryotic RNase P $[8,28]$.

Phenotype changes have been associated with more than 1,500 C. elegans genes through a combination of RNAi screens, classical mutant screens and systematic gene knockout experiments [30-42]. Despite these successes, the functions of most of the approximately 20,000 predicted genes in the $C$. elegans genome remain elusive. Moreover, there were some clear differences in the results of these RNAi screens conducted by different researchers. These differences were considered to result from different approaches and standards in RNAi screening. Furthermore, there was also 10 to $30 \%$ variability in the results of the RNAi screens conducted by the same researcher according to the same procedure $[30,31,34,36-40,43,44]$. The relative variability of the RNAi effect should be an important consideration before the RNAi data are used as starting point for new experiments[40]. In this study, we show that EGS technology can be used to down-regulate gene expression in C. elegans, and the EGS library can facilitate a reverse genetic screen similar to that possible with an RNAi library

\section{Results \\ Validation of EGS technology for down-regulating gene expression in $\mathbf{C}$. elegans}

There are two types of green fluorescent proteins (GFP) in C. elegans strain PD4251. Ngfp consists of a wild-type GFP and a nuclear-localization signal encoded by Ngfp-lacZ. Mtgfp consists of a wild-type GFP and a mitochondriallocalization signal encoded by Mtgfp[45]. EGSs that target to Ngfp-lacZ or Mtgfp mRNA can be designed using RNAfolding software[46]. According to the rules of EGS design[28], the favorable accessible regions of $N g f p$-lacZ (Fig. 1A) and Mtgfp mRNAs (Fig. 1B) were identified from all candidate accessible regions. The "3/4 EGS" (Fig. 1C) was used as the framework. The anti-sense sequence of the accessible region was introduced into the antisense domain of the framework. The "CCA" sequence $[7,8,28,47,48]$ located in the 3 '-terminus is important for the EGS effect. To protect the "CCA" sequence from being exposed directly to RNase, the "UUU" sequence was attached to its 3'-terminus. Two EGSs, EGS-Ngfp-lacZ (Fig. 1D) and EGS-Mtgfp (Fig. 1F), were constructed. Two additional EGSs, EGS-Ngfp-lacZ-D (Fig. 1E) and EGS-Mtgfp-D (Fig. 1G), were also constructed. EGS-Ngfp-lacZ-D and EGS-Mtgfp-D were derived from EGS-Ngfp-lacZ and EGS-Mtgfp, respectively, and contained point mutations (5'-TTC-3' $\rightarrow$ AAG) at the three highly conserved positions in the "T-loop" of these EGSs. These nucleotides have been found in most of the known, natural tRNA sequences[49] and are thought to be important for interactions between the tRNA domains and human RNase P[3]. Previous studies have shown that EGSs with these mutations prevented RNase P recognition and showed little activity in directing RNase-P-mediated cleavage[19,50,51].

To determine the efficacy of the EGSs in inhibiting the expression of their targets, PD4251 worms were treated with EGS-Ngfp-lacZ, EGS-Mtgfp, a mix of EGS-Ngfp-lacZ and EGS-Mtgfp, EGS-Ngfp-lacZ-D, EGS-Mtgfp-D, or a mix of EGS-Ngfp-lacZ-D and EGS-Mtgfp-D. In contrast to worms treated with soaking buffer (Fig. 2A), worms treated with EGS-Ngfp-lacZ (Fig. 2C) or EGS-Mtgfp (Fig. 2E) showed a partial reduction in GFP fluorescence. GFP fluorescence almost disappeared in worms treated with a mix of EGS-Ngfp-lacZ and EGS-Mtgfp (Fig. 2G). By contrast, there was no decrease in GFP fluorescence in worms treated with EGS-Ngfp-lacZ-D (Fig. 2B), EGS-Mtgfp-D (Fig. 2D), or a mix of EGS-Ngfp-lacZ-D and EGS-Mtgfp-D (Fig. 2F). The disabled EGSs were able to serve as negative 


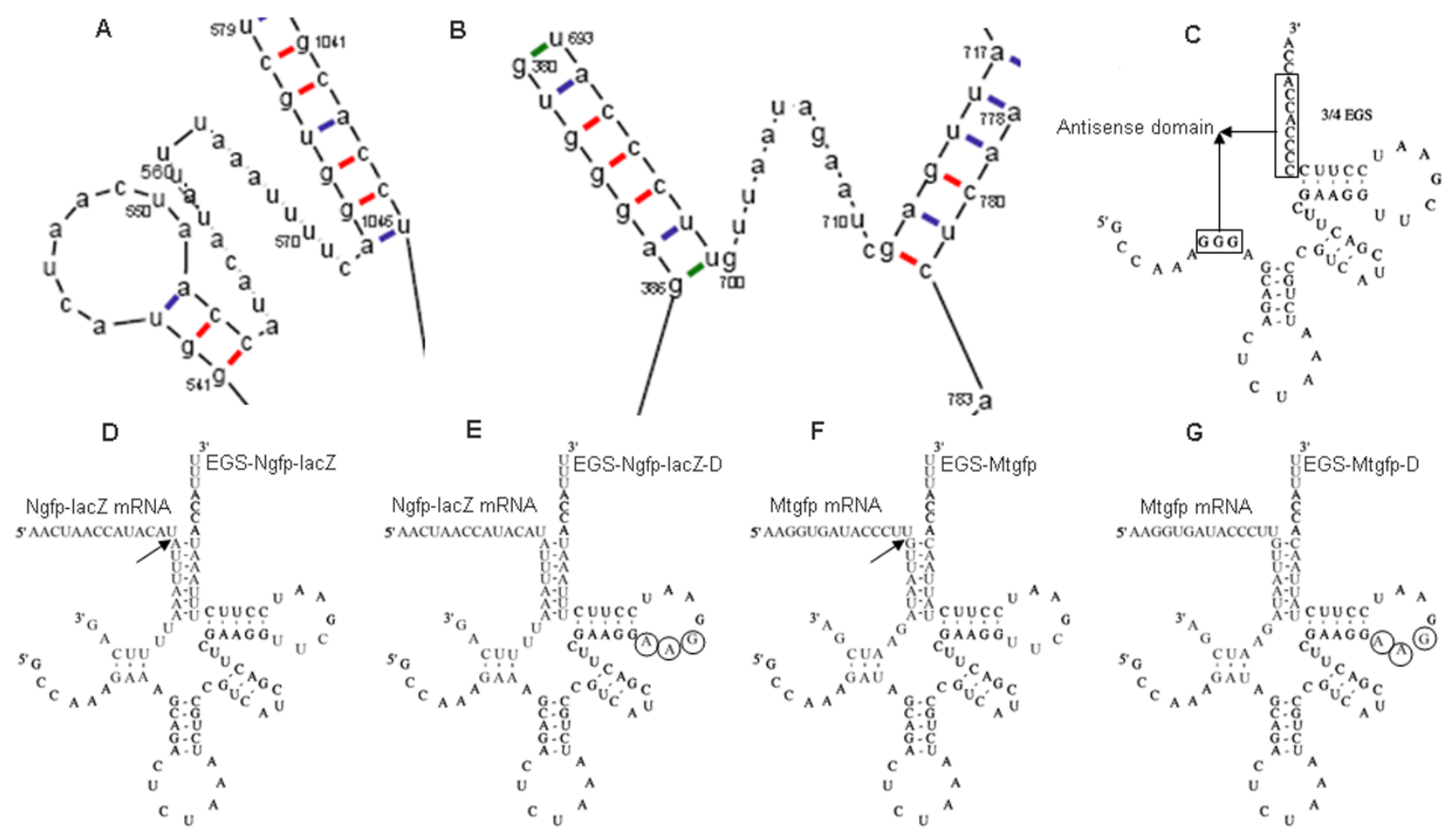

\section{Figure I}

EGSs targeted to Ngfp-lacZ and Mtgfp mRNA. (A) The looped region of "auuuaaauuuuc" was chosen as a target region for EGS-Ngfp-lacZ. (B) The looped region of "guuaauagaauc" was chosen as a target region for EGS-Mtgfp. (C) The "3/4 EGS" derived form was a precursor of tRNA ${ }^{T y r}$ in Escherichia coli. (D, E) Complex between Ngfp-lacZ mRNA and EGS-Ngfp-lacZ (D) or EGS-Ngfp-lacZ-D (E). The arrow indicates the site of cleavage by RNase P. EGS-Ngfp-lacZ-D is derived from EGS-Ngfp-lacZ by introducing base-substitution mutations at three positions (highlighted by circles) in the T-loop. (F, G) Complexes between the MtgfP mRNA and EGS-Mtgfp or EGS-Mtgfp-D, respectively. The arrow indicates the site of RNase P cleavage. EGS-Mtgfp$\mathrm{D}$ is derived from EGS-Mtgfp by introducing base-substitution mutations at three positions (highlighted by circles) of the Tloop.

controls that cannot function effectively for RNase Pbased targeting.

The expression level of GFP mRNA was determined by quantitative PCR (QPCR) analysis (Fig. 3A and Table 1). Reductions of $34 \%$ and $40 \%$ in the expression level of GFP mRNA were observed in worms treated with EGSNgfp-lacZ and EGS-Mtgfp, respectively. There was a marked reduction of $96 \%$ in the expression level of GFP mRNA in worms treated with a mix of EGS-Ngfp-lacZ and EGS-Mtgfp. By contrast, the expression level of GFP mRNAs was reduced by $<10 \%$ in worms treated with EGSNgfp-lacZ-D, EGS-Mtgfp-D, or a mix of EGS-Ngfp-lacZ-D and EGS-Mtgfp-D. These results indicate that these EGSinduced significant reductions in the target mRNA expression level were due to RNase P-mediated cleavage. The low level of inhibition in worms treated with these disabled EGSs was presumably due to an anti-sense effect of the EGS.
To examine the targeting specificity of EGS-Ngfp-lacZ and EGS-Mtgfp, the protein levels of Ngfp and Mtgfp were determined by Western-blot analysis (Fig. 3B and Table $1)$. Reductions of $56 \pm 5 \%$ and less than $10 \%$ in the levels of Ngfp and Mtgfp proteins, respectively, were observed in worms treated with EGS-Ngfp-lacZ. Similarly, there were reductions of $70 \%$ and less than $10 \%$ in the levels of Mtgfp and Ngfp proteins, respectively, in worms treated with EGS-Mtgfp. Interestingly, greater reductions of $71 \pm$ $6 \%$ and $95 \%$ in the level of Ngfp and Mtgfp proteins, respectively, were observed in worms treated with a mix of EGS-Ngfp-lacZ and EGS-Mtgfp. By contrast, Ngfp and Mtgfp protein levels were reduced by $<10 \%$ in worms treated with EGS-Ngfp-lacZ-D, EGS-Mtgfp-D or a mix of EGS-Ngfp-lacZ-D and EGS-Mtgfp-D. The small reductions in the Ngfp and Mtgfp protein expression levels in worms treated with these disabled EGSs were likely due to antisense effects of the EGSs. 

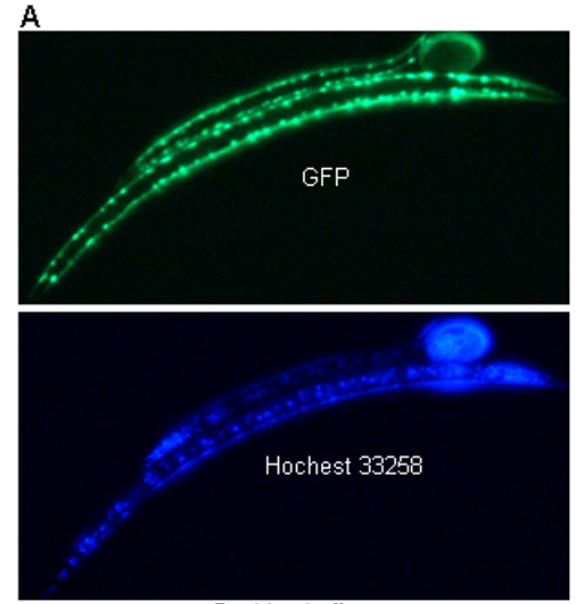

Soaking buffer
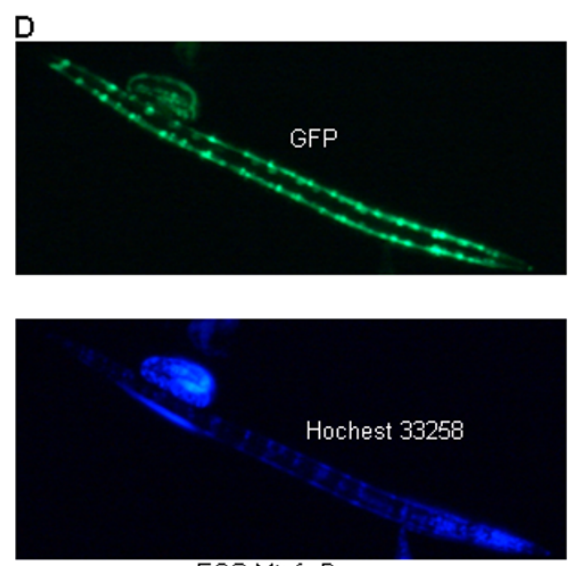

EGS-Mtgfp-D
B
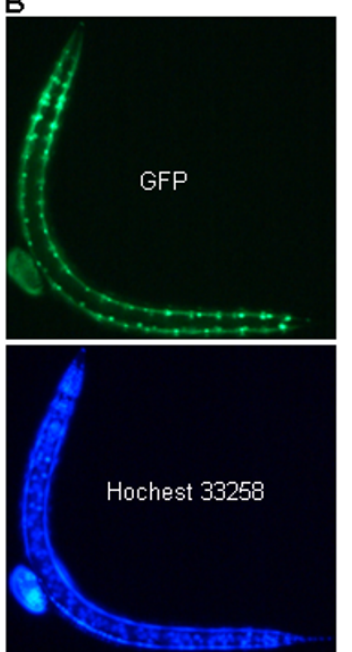

EGS-Ngfp-lacZ-D

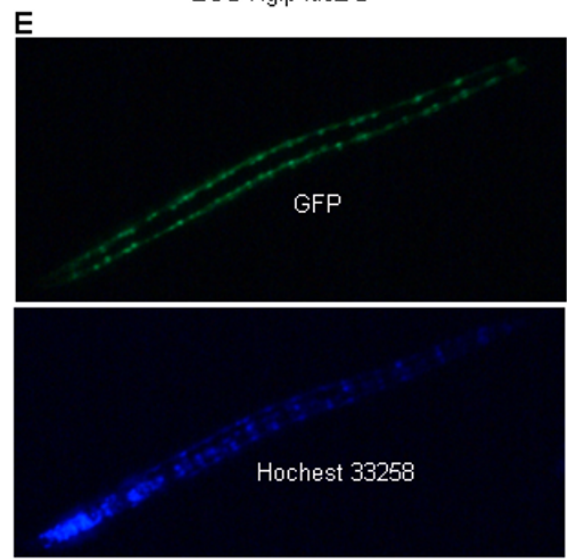

EGS-Mtgfp

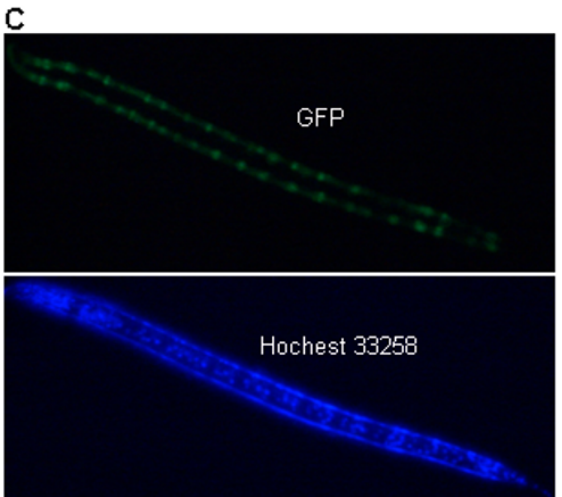

EGS-Ngfp-lacZ

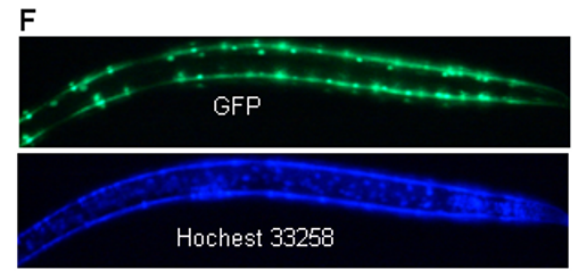

EGS-Ngfp-lacZ-D + EGS-Mtgfp-D

G

GFP

Hochest 33258

EGS-Ngfp-lacZ + EGS-Mtgfp

Figure 2

Effects of EGS on GFP fluorescence of PD425 I worms. (A) Worms were treated with soaking buffer. (B, D, F) Worms were treated with disable EGSs (EGS-Ngfp-lacZ-D (B), EGS-Mtgfp-D (D), or a mix of EGS-Ngfp-lacZ-D and EGS-Mtgfp-D (F)). (C, E, G) Worms were treated with EGSs (EGS-Ngfp-lacZ (C), EGS-Mtgfp (E), or a mix of EGS-Ngfp-lacZ and EGS-Mtgfp (G)). To locate the nuclei, worms were stained with Hoechst 33258 stain.

Table I: Levels of inhibition of the expression of Ngfp and Mtgfp

\begin{tabular}{|c|c|c|c|}
\hline Treatment & GFP mRNA & Ngfp protein & Mtgfp protein \\
\hline Soaking buffer & $0 \%$ & $0 \%$ & $0 \%$ \\
\hline EGS-Ngfp-lacZ & $34 \%$ & $56 \% \pm 5 \%$ & $5 \%$ \\
\hline EGS-Ngfp-lacZ-D & $4 \%$ & $6 \%$ & $4 \%$ \\
\hline EGS-Mtgfp & $40 \%$ & $5 \%$ & $70 \%$ \\
\hline EGS-Mtgfp-D & $7 \%$ & $4 \%$ & $6 \%$ \\
\hline Mix of EGS-Ngfp-lacZ and EGS-Mtgfp & $96 \%$ & $71 \% \pm 6 \%$ & $95 \%$ \\
\hline Mix of EGS-Ngfp-lacZ-D and EGS-Mtgfp-D & $8 \%$ & $7 \%$ & $8 \%$ \\
\hline
\end{tabular}

Inhibition of the expression of NgfP and Mtgfp in PD425I worms that were treated with EGS, compared with the levels of inhibition in PD425I worms that were treated with soaking buffer. The values shown are means derived from triplicate experiments, and values for the standard deviation that were less than $5 \%$ are not shown. 
A

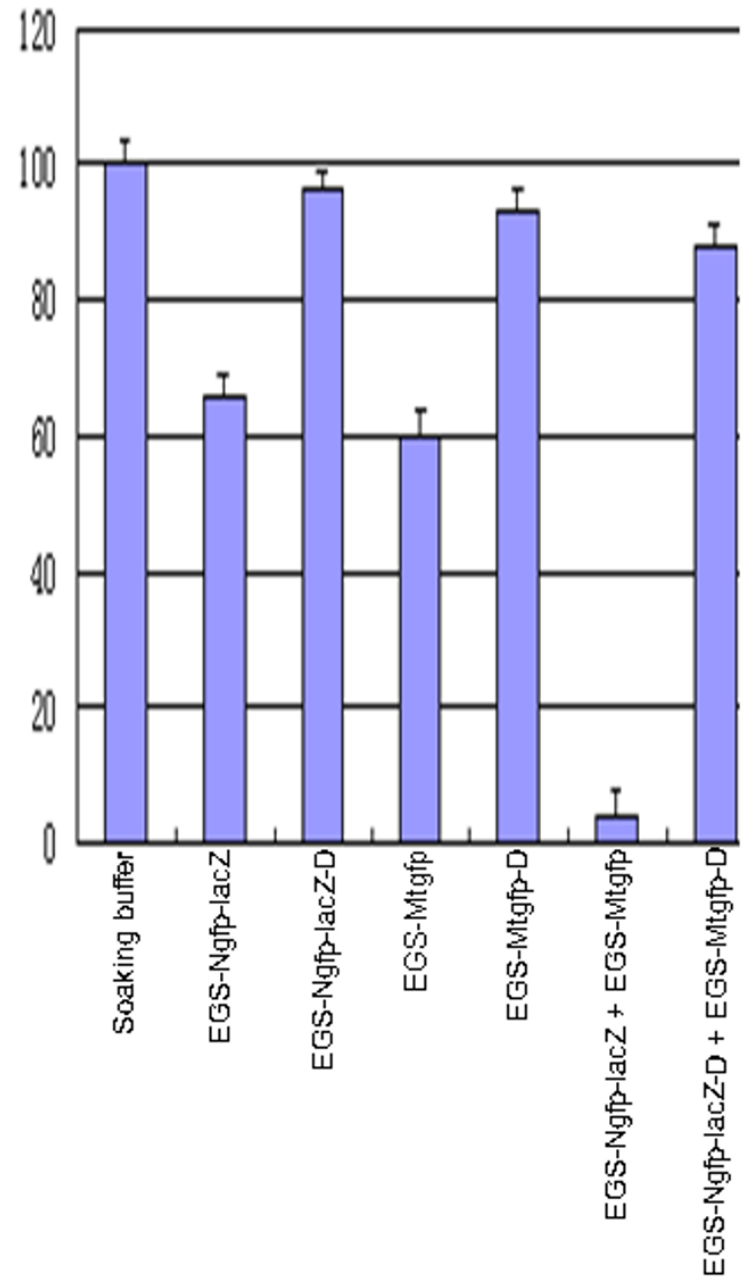

B

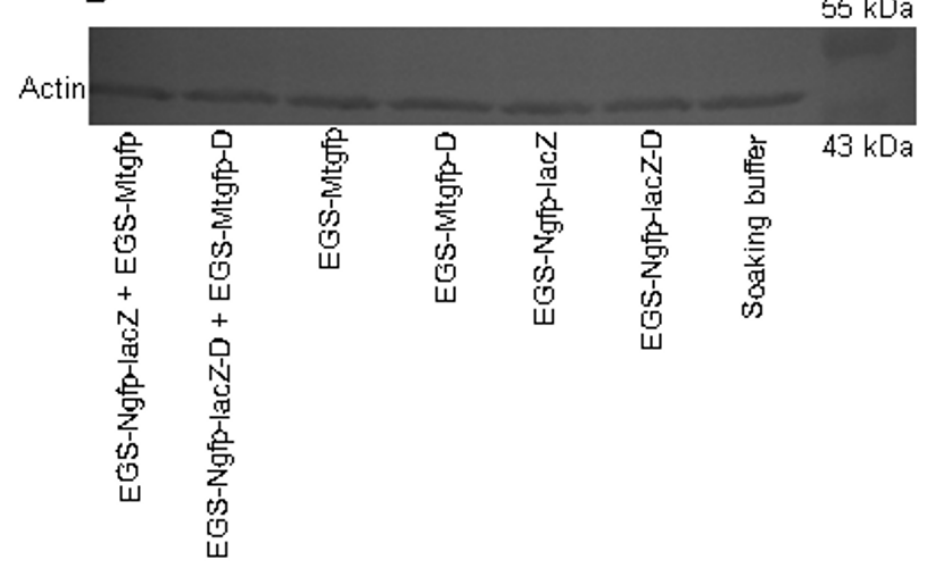

Figure 3

(A) Effects of EGS on expression levels of GFP mRNA in PD425I worms. Shown is the GFP mRNA expression level, as measured by QPCR. (B) Effects of EGS on expression levels of Noff and Mtgfp proteins in PD425I worms treated with EGSs. Shown are the Ngfp and Mtgfp protein expression levels, as measured by Western-blot analysis. Actin protein was used as an internal control.

\section{Generation of EGS library}

The "3/4 EGS" (Fig. 4A) was used as a framework for the EGS library. The EGS library (Fig. 4B), which contains a randomized anti-sense domain of the "3/4 EGS", was generated by introducing the following modifications into the framework: the anti-sense domain was composed of random bases; The "CCA" sequence $[7,8,28,47,48]$ located in the 3 '-terminus is important for the EGS effect. To protect the "CCA" sequence from being exposed directly to RNase, the "UUU" sequence was attached to its 3'-terminus. The resulting EGS library is a collection that contains any EGS targeted to any target mRNA (Fig. 4C).

pET28a-LEGS, which contains the EGS library cassette under control of T7 promoter, was constructed (Fig. 5).
First, a primer pair of FLESp and RLEGSp was designed (Fig. 6). The partially randomized oligonucleotides of FLESp and RLEGSp were composed of two parts; one acted as a primer to amplify pET28a-D equal to pET28a but lacked the fragment between the T7 terminator and T7 promoter. The other acted as a primer to amplify the EGS library cassette. Second, pET28a-LEGSL was amplified by PCR with the primer pair of FLEGSp and RLEGSp using pET28a as template. Third, pET28a-LEGS was constructed by self-ligation of pET28a-LEGSL and transformed into DH5 $\alpha$ to screen for pET28a-EGS clones containing individual EGS cassettes.

In general, about $98 \%$ of pET28a-EGS clones have one HincII site, with the remaining $2 \%$ having two or three 


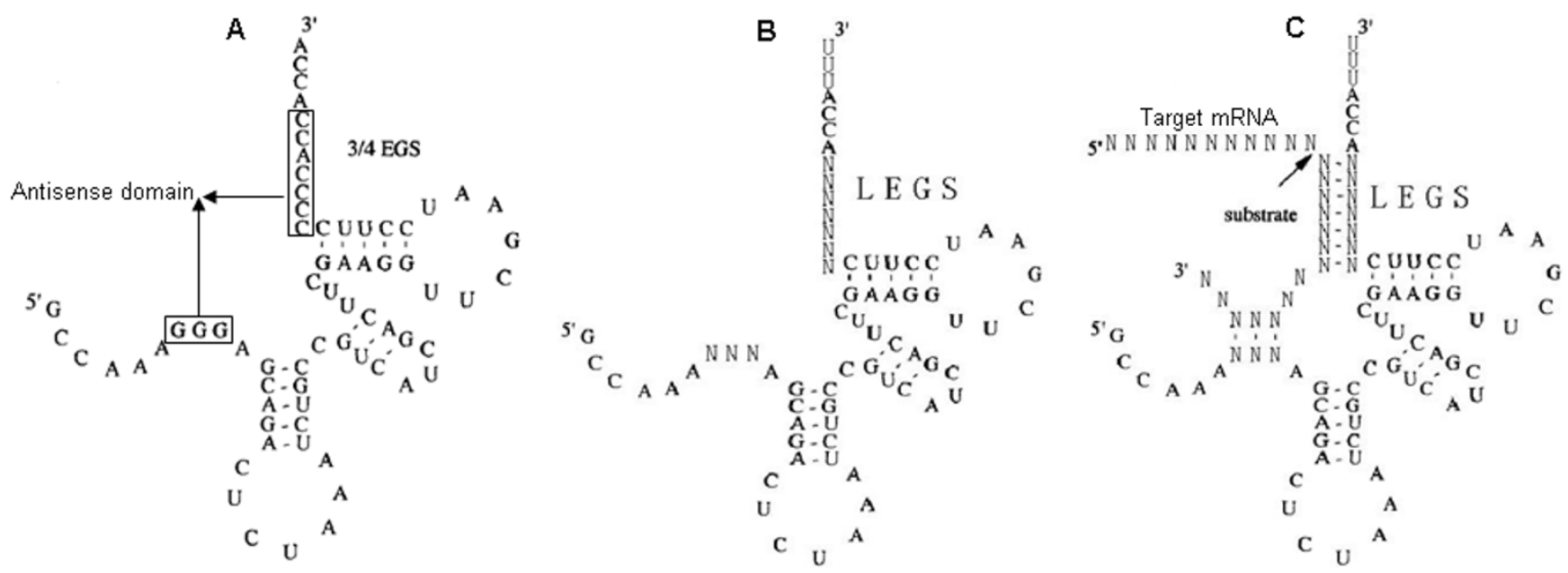

Figure 4

Demonstration of EGS library. (A) The "3/4 EGS" is derived from a precursor of tRNATyr in Escherichia coli. (B) EGS library. The anti-sense domain is composed of random bases. (C) The complex of EGS library and any potential target mRNA. The arrow indicates the RNase $P$ cleavage site.

HincII sites. Their HincII digestion patterns were predicted by the NTI program (Fig. 7A). To examine the composition of the EGS library, 500 clones were chosen at random for restriction enzyme (HincII) analysis. Of these 500 clones, 94\% (Fig. 7B) showed the HincII digestion pattern shown in Fig. 7A, lane RV1, the rest (see Additional file 1) showed the HincII digestion pattern shown in Fig. 7A, lane RV2. Sequence analysis was performed to determine the specific sequences; $94 \%$ were shown to have a unique EGS cassette sequence. Alignment analysis was used to show that these sequences (Fig. 7C) showed no bias in cloning of certain EGS cassettes.

\section{Validation of EGS library for reverse genetic screen in C. elegans}

To examine whether the EGS library can be used as a reverse genetic screen in C. elegans, 300 unique EGSs were randomly selected and used for screening of the C. elegans strain N2. The screening procedure is systemically shown in Fig. 8. First, the EGS clone IVTT containing an EGS cassette controlled by the T7 promoter was amplified by PCR with the primers Fclone-IVTT and Rclone-IVTT, using the pET28a-EGS clone as a template (Fig. 8A, B). An EGS clone was transcribed by T7 RNA polymerase using the purified EGS-clone IVTT as a template (Fig. 8A, C). Second, synchronous cultures of N2 worms were soaked in EGS solution. These worms were individually transferred to new plates with food, and phenotypes of both P0 worms and F1 progenies were recorded (Fig. 8D). All phenotypes visible under the dissection microscope were recorded. Such phenotypes included sterility, slow postembryonic growth, larval arrest, larval lethality, abnormal morphology, and uncoordination. About $6 \%$ of EGSs induced abnormal phenotypes, such as P0 slow postembryonic growth, P0 larval arrest, P0 larval lethality and P0 sterility (Table 2). Of these, EGS-35 and EGS-83 (Fig. 9A, C) caused the greatest phenotype changes (Table 2). The target mRNAs of EGS-35 and EGS-83 were identified by the following procedure. All candidate target mRNAs of an EGS were identified by a BLAST search of its target sequence (see Additional file 2). BLAST searches of all EGS-35 and EGS-83 candidate target sequences (Table 3 ) produced 12 and 34 candidate mRNAs (Table 4, 5), respectively. The expression levels of all candidate target mRNAs in worms treated with EGS-35 or EGS-83 were analyzed by QPCR (Tables 6, 7). In worms treated with EGS-35, there were $64 \%$ and $<10 \%$ reductions in the expression levels of ZK858.7 mRNA [Genbank: NM 060051.2] and the other candidate mRNAs, respectively. In worms treated with EGS-83, there were reductions of $72 \%$ and $<10 \%$ in the expression levels of lin-13 mRNA [Genbank: NM 066277.3] and the other candidate mRNAs, respectively. By contrast, a reduction of $<10 \%$ in all candidate target mRNAs was observed in worms treated with EGS-35-D or EGS-83-D (Fig. 9B, D). These small reductions in worms treated with the disabled EGS were likely due to anti-sense effects of the EGSs. These results indicate that the significant reductions in the levels of target mRNA expression (ZK858.7 mRNA and Lin-13 mRNA for EGS-35 and EGS-83, respectively) in worms treated with EGSs were due to EGS-directed RNase-Pmediated cleavage. The phenotypes of worms with RNAiZK858.7 mRNA and RNAi-Lin-13 mRNA were similar to the phenotypes induced by EGS-35 and EGS-83, respectively (Table 2). 

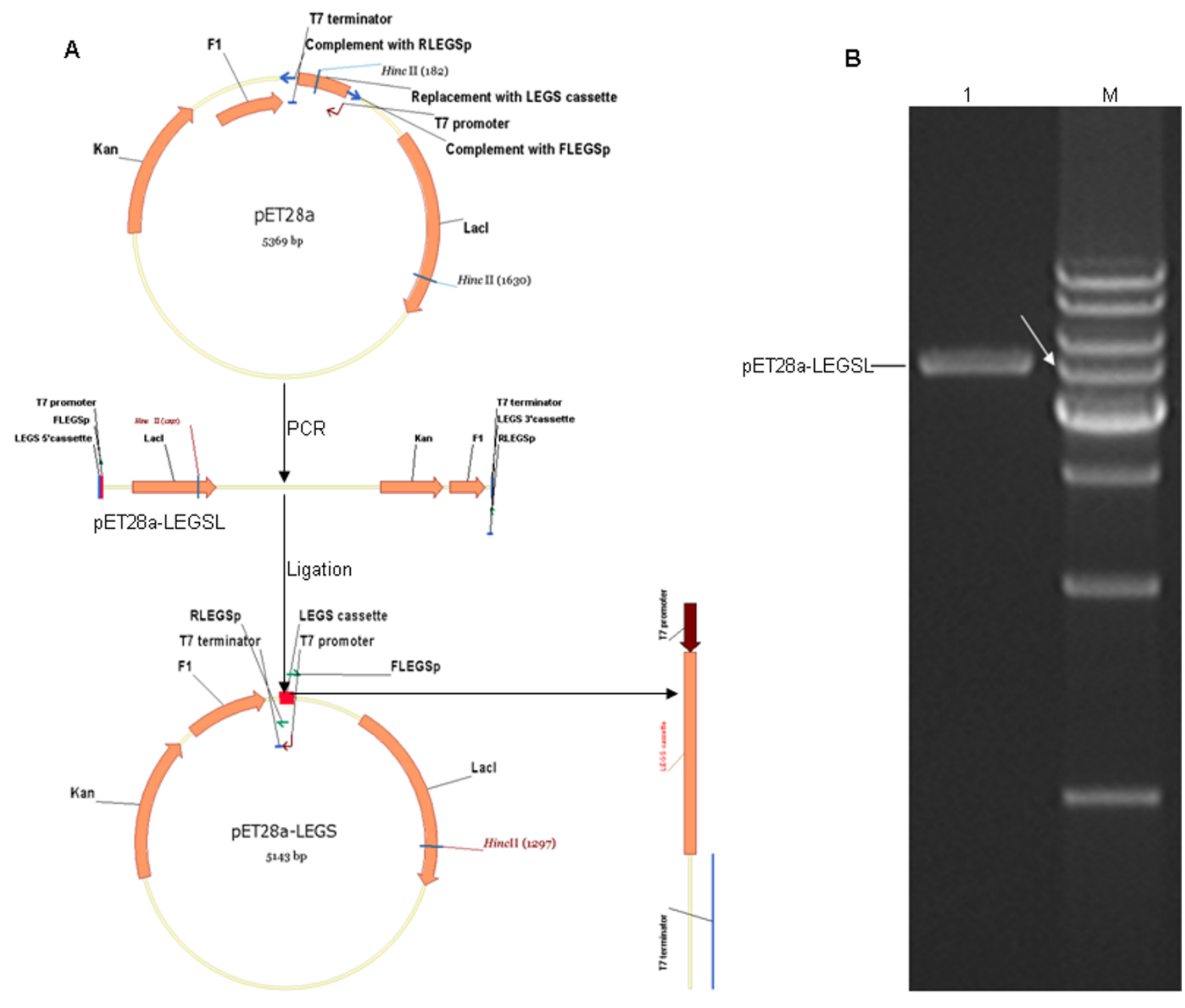

\section{Figure 5}

Construction of pET28a-LEGS. (A) Flow chart showing the construction of pET28a-LEGS. (B) The PCR product of pET28a-LEGSL (lane I). The arrow indicates the 5-kb DNA band (lane M).

\section{Discussion}

It has been shown that EGS technology can be used to down-regulate gene expression in bacteria [9-12], mammalian cells [13-19] and maize cells[20]. We have shown that EGS technology can also be used to down-regulate gene expression in C. elegans. Several criteria must be satisfied if successful EGS targeting is to be achieved. Among these are high cleavage efficiency, EGS target specificity, and efficient delivery of the reagent. We constructed EGSNgfp-lacZ and EGS-Mtgfp that target Ngfp-lacZ and Mtgfp mRNAs, respectively, and showed that these EGSs direct RNase P to cleave the targets efficiently. Moreover, we showed targeting specificity of these EGSs. Although the complementary sequence of anti-sense domain of EGSNgfp-lacZ is present in Mtgfp mRNA, a small reduction in the Mtgfp protein expression level was observed in worms treated with EGS-Ngfp-lacZ. In addition, Ngfp-lacZ mRNA contains the complementary sequence of the anti-sense domain of EGS-Mtgfp, but there was a small reduction in the Ngfp protein expression level in worms treated with EGS-Mtgfp. Reduction of $<10 \%$ in the expression levels of Ngfp and Mtgfp proteins were observed in worms treated with EGS-Ngfp-lacZ-D or EGS-Mtgfp-D, respectively. Together, these results indicate that the significant reductions in the Ngfp and Mtgfp protein expression levels in worms that treated with EGS-Ngfp-lacZ and EGS-Mtgfp, 
Part 1 of EGS library cassette

\begin{tabular}{l} 
AAATGGTNNNNNNNGAAGGATTCGAACCTTCGAAG TCGATGACGGCAGATTTAGAGTCTGCTNNNTTTGGC \\
TTTACCA NNNNNNNCTTCCTAAGCTTGGAAGCTTC AGCTACTGCCGTCTAAATCTCAGACGANNNAAACCG \\
\hline
\end{tabular}

Part 2 of EGS library cassette

Antisense strand of EGS library cassette

\begin{tabular}{|c|c|c|c|}
\hline \multirow[b]{2}{*}{ Amplify Antisense strand of pET28a-D } & \multirow{2}{*}{ Antisense strand of part 2 of EGS library cassette } & Sense strand of part 1 of EGS library cassette & Amplify sense strand of pET28a-D \\
\hline & & TCGATGACGGCAGATTTAGAGTCTGCTNNNTTTGGC & TATAGTGAGTCGTATTAATTTCG \\
\hline TCTCCGGGGTTCCCCAATACGAT & ITACCANNNNNNNCTTCCTAAGCTTGGAAGCTTC & FLEGSp & \\
\hline
\end{tabular}

\section{Figure 6}

Demonstration of FLEGSp and RLEGSp. The partially randomized oligonucleotides of FLESp and RLEGSp are composed of two parts. One is used to amplify PET28a-D, which is equal to pET28a but does not contain the fragment between the T7 terminator and T7 promoter. The other is used to amplify the EGS library cassette.

respectively, were primarily due to EGS-induced RNase-Ptargeted cleavage rather than anti-sense effects or other nonspecific effects of the EGSs. The mix of EGS-Ngfp-lacZ and EGS-Mtgfp had greater effects on inhibition of NgfplacZ and Mtgfp expression compared with individual EGSNgfp-lacZ and individual EGS-Mtgfp, respectively (Fig. 3B and Table 1). This was probably due to anti-sense effects of the EGSs, but is not due to any overlap in the target sequence. Maybe the EGS methodology is particularly effective when more than one site in a particular mRNA is targeted[12,16].

Many C. elegans genes have been associated with phenotypes due to the results of reverse genetic screens based on RNAi libraries. Despite the success of these screens, the functions of most of approximately 20,000 predicted genes in the C. elegans genome remain elusive. Moreover, the limitations of RNAi such as off-target [52-54] and relative variability in the RNAi effect[40] compromise the level of confidence in the results of these RNAi screens. The EGS library aims to facilitate reverse genetic screens such as those with the RNAi library, and it will be useful for confirming RNAi phenotypes. For example, ZK858.7 and lin-13 genes were identified by a reverse genetic screen based on the EGS library. Remarkably, EGS-35 and EGS83 efficiently and specifically interfered with ZK858.7 and lin-13, respectively. The target specificity of the EGS is governed by two different types of interactions [3,19]. One is the base-pairing interactions $[3,17,19,55]$ in which the ten nucleotides in the EGS hybridize with the accessible region of the target mRNA. The EGS has two short, sequence-specific recognition elements that are oriented in space with respect to each other in a well-defined fashion. This complex recognition element provides the necessary specificity for RNase P. It is known that the ten nucleotides involved in base-pairing between the EGS and the target mRNA make it difficult to guarantee target specificity in C. elegans. Given the extensive secondary and tertiary structure associated with the RNA or the binding of proteins to the target RNA in vivo, the target sequences in cellular RNAs are not all accessible. The other type of interaction $[3,17,19,55]$ is between the RNase P recognition domain (e.g., T-loop and stem) and the mRNA. This interaction facilitates the folding of the EGS-mRNA complex into a tRNA-like molecule and stabilizes the mRNAEGS complex. An immediate corollary is that if two targets with a one-bp mismatch are compared, the same caveat on accessibility rules out any meaningful comment on specificity of targeting. Mutation of a single base in the target mRNA will not affect the methodology based on "stem EGS" because a single base mismatch in the complex with the target mRNA is unlikely to alter recognition by RNase $P[9,12]$. However, the location of the unpaired nucleotides is important because three contiguous unpaired bases might very well disallow the RNase P-mediated effects. It is that an EGS could still function despite several point mutations between it and the bacterial target mRNA, depending precisely on the sequence of the unpaired bases[9]. The framework of EGS-35 and EGS-83 is the "3/4 EGS" that is distinguishable from the "stem EGS" by additional parts equivalent to the T-stem and Tloop, and variable regions of a tRNA. The mismatch tolerance of the effects of EGS-35 and EGS-83 needs further study. Since the worms are cultured at $20^{\circ} \mathrm{C}$, specificity 
A B
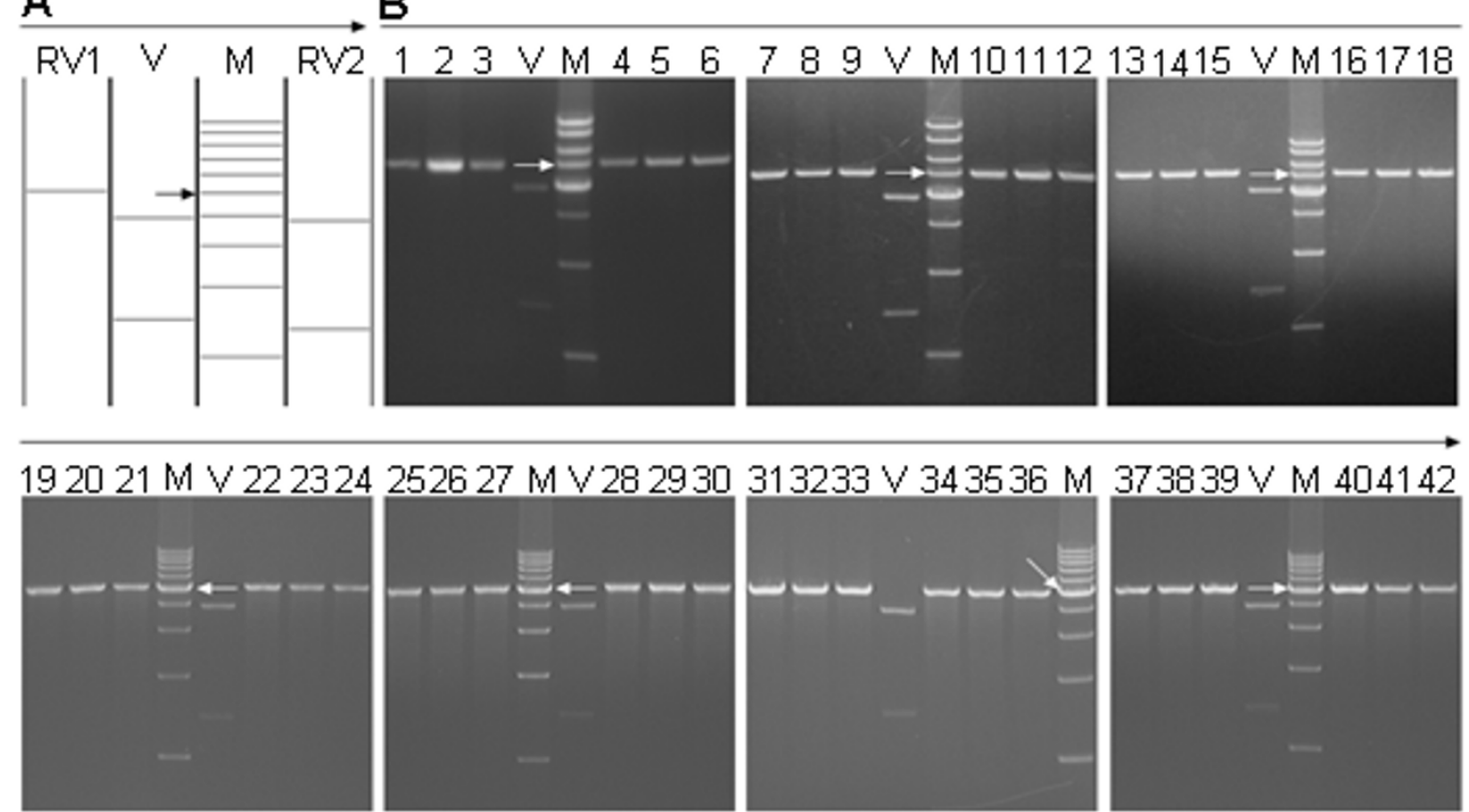

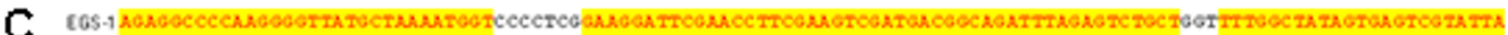

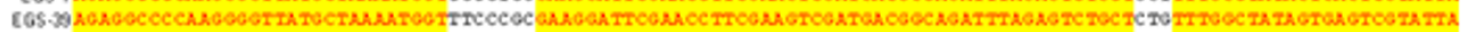

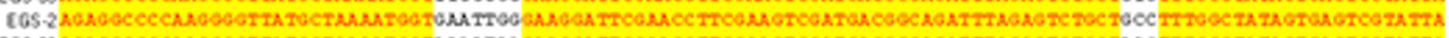

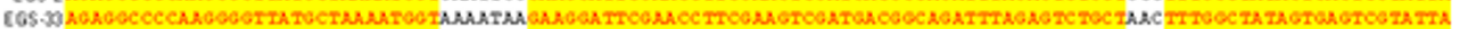

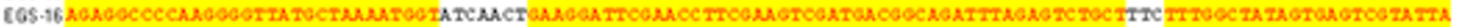

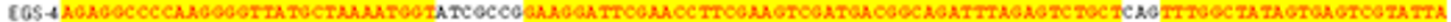

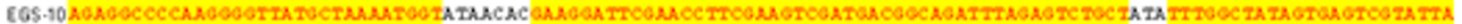
EOS.17 Aos

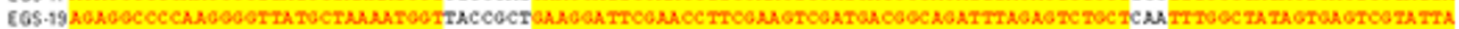

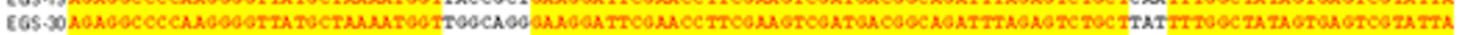

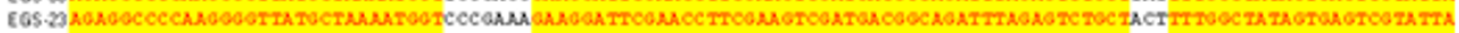

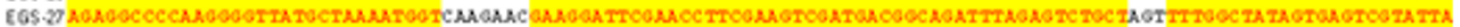

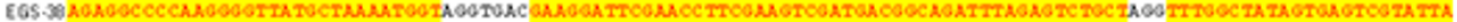

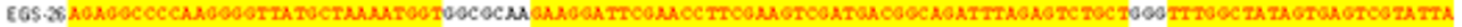
E0S.3A.9A0OCCCCA

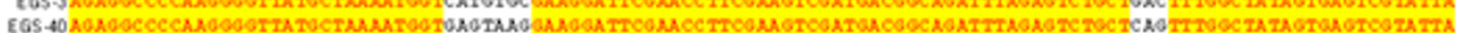

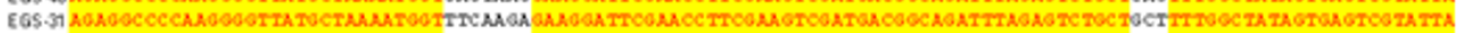

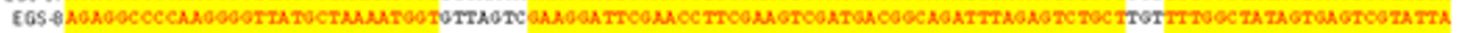

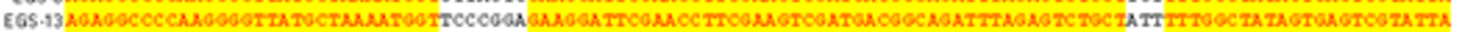

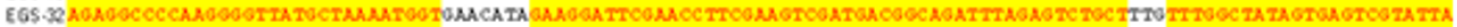

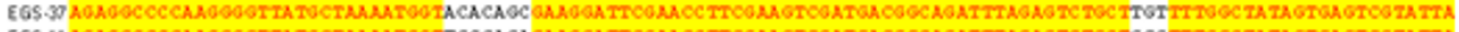

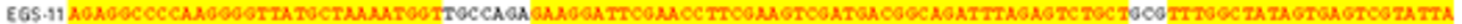

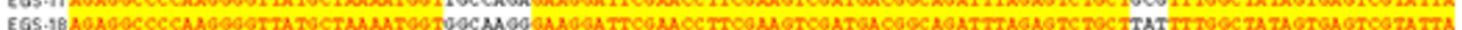

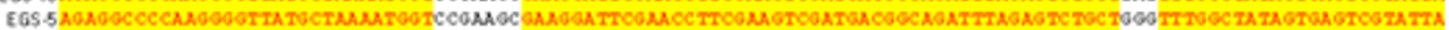

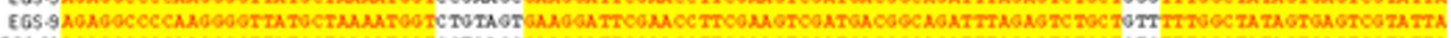

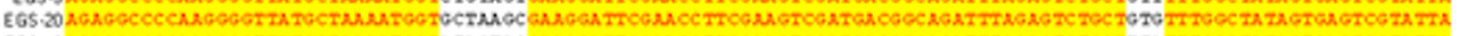

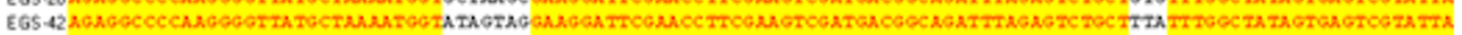

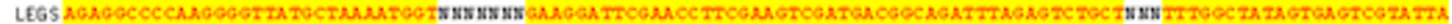

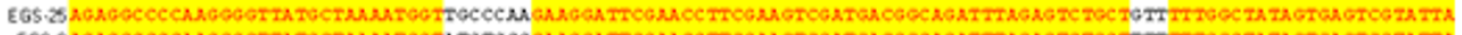

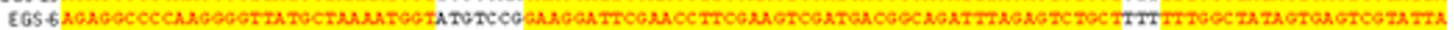

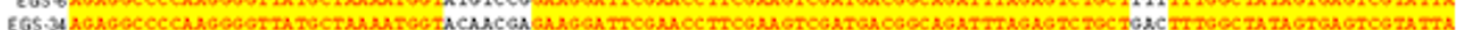

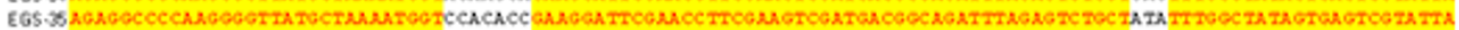

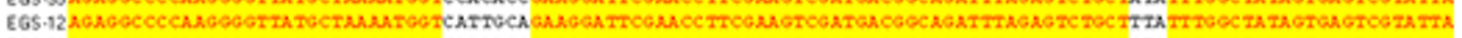

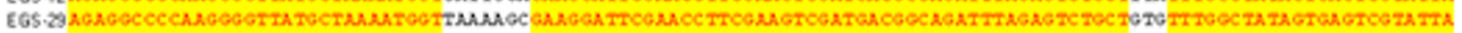
EGS.24 A

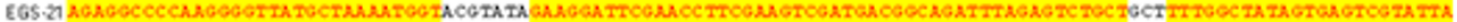

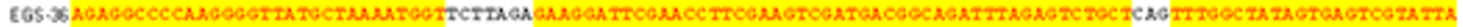

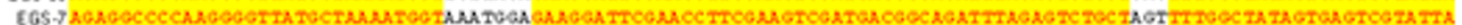

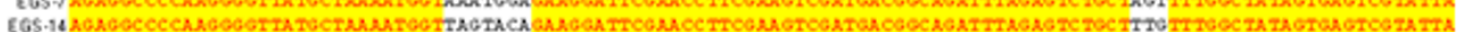

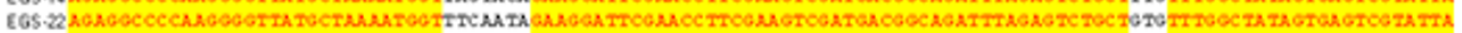

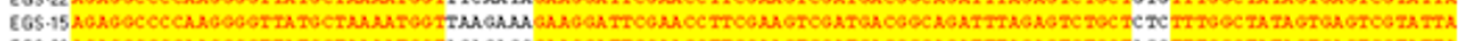

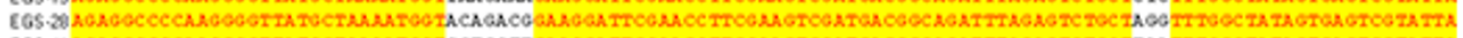

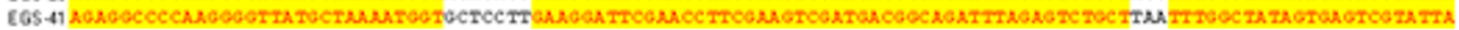

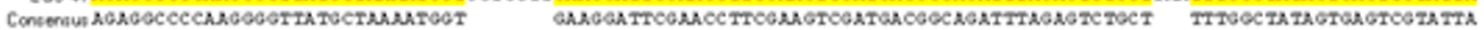

\section{Figure 7}

Examination of composition of the EGS library. (A) Hincll digestion patterns of the pET28a-EGS clone (lane RVI) containing one Hincll site, the pET28a-EGS-clone (lane RV2) containing two or three Hincll sites, and pET28a (lane V). The arrow indicates the 5-kb DNA band (lane M). (B) The Hincll digestion products of the PET28a-EGS clones containing one Hincll site (lanes I-42) and pET28a (lane V). The arrows indicate the 5-kb DNA band (lane M). (C) The alignment of sequences of some EGS cassettes. 
Table 2: Phenotypes induced by certain EGSs

\begin{tabular}{|c|c|c|c|}
\hline EGS clone & Phenotype & Target & Corresponding RNAi phenotype \\
\hline EGS-8 & sterile & & \\
\hline EGS-26 & sterile & & \\
\hline EGS-29 & slow postembryonic growth & & \\
\hline EGS-35 & $\begin{array}{l}\text { slow postembryonic growth } \\
\text { sterile }\end{array}$ & ZK858.7 & $\begin{array}{l}\text { Slow growth } \\
\text { dumpy } \\
\text { sterile progeny } \\
\text { embryonic lethal } \\
\text { organism morphology abnormal } \\
\text { maternal sterile } \\
\text { transposon silencing abnormal }\end{array}$ \\
\hline EGS-4I & larval lethality & & \\
\hline EGS-43 & sterile & & \\
\hline EGS-80 & sterile & & \\
\hline EGS-83 & $\begin{array}{l}\text { Sterile } \\
\text { larval arrest }\end{array}$ & Lin- 13 & $\begin{array}{l}\text { Sterile FI } \\
\text { Larval arrest } \\
\text { sterile } \\
\text { multivulva } \\
\text { organism morphology abnormal } \\
\text { protruding vulva }\end{array}$ \\
\hline EGS- 105 & larval lethality & & \\
\hline EGS-1 27 & slow postembryonic growth & & \\
\hline EGS-139 & slow postembryonic growth & & \\
\hline EGS-I56 & sterile & & \\
\hline EGS-189 & sterile & & \\
\hline EGS-20I & larval lethality & & \\
\hline EGS-225 & slow postembryonic growth & & \\
\hline EGS-265 & larval lethality & & \\
\hline EGS-289 & sterile & & \\
\hline EGS-296 & sterile & & \\
\hline
\end{tabular}

Table 3: Candidate targeting sequences of EGS-35 and EGS-83

\begin{tabular}{lll}
\hline EGS & EGS-35 & EGS-83 \\
\hline Outline & GTCGCATNNTCC & GAACATANNTTG \\
All candidate targeting sequences & GTCGCATAATCC & GAACATAAATTG \\
& GTCGACATAATTTG & GAACATAAGTTG \\
& GTCGCATAGTCC & GAACATAACTTG \\
& GTCGCATACTCC & GAACATATATTG \\
& GTCGCATTATCC & GAACATATTTG \\
& GTCGCATTTTCC & GAACATATGTTG \\
& GTCGCATTGTCC & GAACATAGATTG \\
& GTCGCATTCTCC & GAACATAGTTTG \\
& GTCGCATGATCC & GAACATAGGTTG \\
& GTCGCATGTTCC & GAACATAGCTTG \\
& GTCGCATGGTCC & GAACATACATTG \\
GTCGCATGCTCC & GTCGCATCATCC & GAACATACTTTG \\
& GTCGCATCTTCC & GAACATACGTTG \\
\hline
\end{tabular}

The bases marked in bold are not complemented with the EGS 
Table 4: Candidate target mRNAs of EGS-35

\begin{tabular}{|c|c|c|}
\hline Target mRNA & RNAi phenotype & Targeting sequence \\
\hline NM 060051.2 & $\begin{array}{l}\text { slow_growth } \\
\text { dumpy } \\
\text { sterile_progeny } \\
\text { embryonic_lethal } \\
\text { organism_morphology_abnormal } \\
\text { maternal_sterile } \\
\text { transposon_silencing_abnormal }\end{array}$ & GTCGCATAGTCC \\
\hline NM 076865.3 & embryonic_lethal & GTCGCATTTTCC \\
\hline NM 062956.2 & embryonic_lethal & GTCGCATTCTCC \\
\hline NM 066665.3 & $\begin{array}{l}\text { embryonic_lethal } \\
\text { locomotion_abnormal } \\
\text { embryonic_lethal } \\
\text { mitotic_spindle_abnormal_early_emb } \\
\text { maternal_sterile } \\
\text { larval_lethal } \\
\text { reduced_brood_size } \\
\text { P0_sp }\end{array}$ & GTCGCATCGTCC \\
\hline NM 001029738.1 & fat_content_reduced & GTCGCATCCTCC \\
\hline NM 072205.2 & Norrmal & GTCGCATTTTCC \\
\hline NM 061028.1 & Norrmal & GTCGCATTCTCC \\
\hline NM 015227.4 & No record & GTCGCATTTTCC \\
\hline NM 001047396.2 & No record & GTCGCATGGTCC \\
\hline NM 001047395.1 & No record & GTCGCATGGTCC \\
\hline NM 074332.2 & No record & GTCGCATGGTCC \\
\hline NM 068962.3 & No record & GTCGCATCTTCC \\
\hline
\end{tabular}

The accession number refers to the GenBank database.

considerations for antisense-based techniques are different compared to plants/animals whose growth temperatures range from 25 to $37^{\circ} \mathrm{C}$.

\section{Conclusion}

EGS technology can be used to interfere with gene expression in C. elegans. The EGS library is used to facilitate a reverse genetic screen as performed by a RNAi library, and it should be particularly useful for confirming the RNAi phenotype as the function of most of the approximately 20,000 predicted genes in the C. elegans genome remains elusive. Moreover, the limitations of RNAi such as off-target and relative variability in the RNAi effect compromise the level of confidence in the RNAi screen results. Taken together, these observations are potentially of great importance for further our understanding and promoting the development of $C$. elegans genomics.

\section{Methods}

\section{C. elegans, primers and vector}

The N2 and PD4251 strains of C. elegans were provided by the Caenorhabditis Genetics Center (Univ. of Minnesota, St. Paul). The worms were maintained and handled as described previously[56]. Primers used in this work are listed in Table 8 . The pET28a vector was purchased from Merk, Inc.

\section{Synchronous cultures of $\mathbf{C}$. elegans}

Synchronous cultures of C. elegans were prepared basically as described previously[56]. The worms were washed well in $\mathrm{M} 9$ solution (43.6 mM Na $2 \mathrm{HPO}_{4}, 22.0 \mathrm{mM} \mathrm{KH}{ }_{2} \mathrm{PO}_{4}$, $8.6 \mathrm{mM} \mathrm{NaCl}$, and $18.7 \mathrm{mM} \mathrm{NH}_{4} \mathrm{Cl}$ )[34] to completely remove bacteria. Then, they were starved and washed well in $0.25 \times \mathrm{M} 9$ solution.

\section{Preparations of EGS-Ngfp-lacZ, EGS-Mtgfp}

The EGSs that specifically target $N g f p-l a c Z$ or $M t g f p$ mRNAs are designed using RNA-folding software[46]. According to the rules of EGS design[28], the favorable accessible regions of $\mathrm{Ngfp}$-lacZ (Fig. 1A) and Mtgfp mRNAs (Fig. 1B) were identified from all candidate accessible regions. The "3/4 EGS" (Fig. 1C) was used as the design framework. The anti-sense sequence of the accessible region was introduced into the anti-sense domain of the design framework. The "CCA" sequence[7,8,28,47,48] located in the 3'-terminus is important for the EGS effect. To protect the "CCA" sequence from being exposed directly to RNase, the "UUU" sequence was attached to its 3'-terminus. To construct pET28a-EGS-Ngfp-lacZ and pET28a-Mtgfp, which contain EGS-Ngfp-lacZ and EGSMtgfp cassettes, respectively, under the control of the T7 promoter, primer pairs were designed using the NTI program (see Additional file 3 ) and synthesized with 5'-ter- 
Table 5: Candidate target mRNAs of EGS-83

\begin{tabular}{|c|c|c|}
\hline Target mRNA & RNAi phenotype & Targeting sequence \\
\hline NM 066277.3 & $\begin{array}{l}\text { sterile_FI } \\
\text { larval_arrest } \\
\text { sterile } \\
\text { multivulva } \\
\text { organism_morphology_abnormal } \\
\text { protruding_vulva }\end{array}$ & GAACATATCTTG \\
\hline NM 058796.3 & male_morphology_abnormal & GAACATATTTTG \\
\hline NM 066347.2 & Abnormal: unclassified phenotypes & GAACATATTTTG \\
\hline NM 062293.4 & Normal & GAACATAAATTG \\
\hline NM 070343.2 & Normal & GAACATAATTTG \\
\hline NM 074278.2 & Normal & GAACATAACTTG \\
\hline NM 059435.2 & Normal & GAACATAACTTG \\
\hline NM 072012.1 & Normal & GAACATATTTTG \\
\hline NM 059793.2 & Normal & GAACATATTTTG \\
\hline NM 076117.3 & Normal & GAACATATATTG \\
\hline NM 059858.2 & Normal & GAACATATATTG \\
\hline NM 061811.2 & Normal & GAACATATATTG \\
\hline NM 073812.2 & Normal & GAACATACCTTG \\
\hline NM 076627.2 & Normal & GAACATACATTG \\
\hline NM 069246.2 & Normal & GAACATACTTTG \\
\hline NM 061292.2 & Normal & GAACATACTTTG \\
\hline NM 063842.2 & Normal & GAACATAGGTTG \\
\hline NM 072852.1 & Normal & GAACATAGTTTG \\
\hline NM 066363.2 & No record & GAACATAAATTG \\
\hline NM 001028778.1 & No record & GAACATAACTTG \\
\hline NM 171639.2 & No record & GAACATATTTTG \\
\hline NM 171942.1 & No record & GAACATATTTTG \\
\hline NM 171638.2 & No record & GAACATATTTTG \\
\hline NM 001028115.1 & No record & GAACATATCTTG \\
\hline NM 001028116.1 & No record & GAACATATCTTG \\
\hline NM 001028113.1 & No record & GAACATATCTTG \\
\hline NM_001028II4.I & No record & GAACATATCTTG \\
\hline NM 001027086.1 & No record & GAACATATCTTG \\
\hline NM 001027085.1 & No record & GAACATATCTTG \\
\hline NM 001029358.2 & No record & GAACATACATTG \\
\hline NM 001029357.3 & No record & GAACATACATTG \\
\hline NM 001029356.1 & No record & GAACATACATTG \\
\hline NM 00102837I.I & No record & GAACATACTTTG \\
\hline NM 001013620.3 & No record & GAACATAGATTG \\
\hline
\end{tabular}

The accession number refers to the GenBank database.

minal phosphorylation modification. The pET28a-EGSNgfp-lacZ and pET28a-Mtgfp constructs were generated (see Additional files 4, 5). pET28a-EGS-Ngfp-lacZL was amplified by PCR with the primer pair of FEGSp-NgfplacZ and REGSp-Ngfp-lacZ using pET28a as a template; the reaction conditions were $98^{\circ} \mathrm{C}$ for $60 \mathrm{~s}, 30$ cycles of $98^{\circ} \mathrm{C}$ for $5 \mathrm{~s}, 70^{\circ} \mathrm{C}$ for $15 \mathrm{~s}$ and $72^{\circ} \mathrm{C}$ for $90 \mathrm{~s}$, followed by $72^{\circ} \mathrm{C}$ for $10 \mathrm{~min}$, in $50-\mu \mathrm{l}$ volumes with Phusion DNA Polymerase (NEB: F-530S). PCR amplification of pET28aEGS-MtgfpL was performed as described above using the primer pair of FEGSp-Mtgfp and REGSp-Mtgfp. The purified PCR products were self-ligated by T4 ligase (NEB) at $15^{\circ} \mathrm{C}$ for 16 hours. The ligation product was transformed into DH5 $\alpha$-competent cells and screened with $30 \mu \mathrm{g} / \mathrm{ml}$ kanamycin. The recombinant vectors of pET28a-EGS-
Ngfp-lacZ and pET28a-EGS-Mtgfp were identified by restriction enzyme digest with HincII and sequencing with the S-LEGS-F or S-LEGS-R primers. In vitro transcriptions of EGS-Ngfp-lacZ and Mtgfp were demonstrated (see Additional file 6). PCR amplification of EGS-Ngfp-lacZIVTT was performed with the primer pair of FNgfp-lacZIVTT and RNgfp-lacZ-IVTT using pET28a-EGS-Ngfp-lacZ as a template; the reaction conditions were $98^{\circ} \mathrm{C}$ for $60 \mathrm{~s}$, 30 cycles of $98^{\circ} \mathrm{C}$ for $5 \mathrm{~s}, 70^{\circ} \mathrm{C}$ for $15 \mathrm{~s}$, and $72^{\circ} \mathrm{C}$ for 15 $\mathrm{s}$, followed by $72^{\circ} \mathrm{C}$ for $10 \mathrm{~min}$, in $50-\mu \mathrm{l}$ volumes with Phusion DNA Polymerase (NEB: F-530S). PCR amplification of EGS-Mtgfp-IVTT was performed as described above but using pET28a-EGS-Mtgfp as a template and the primer pair of RMtgfp-IVTT and FMtgfp-IVTT. EGS-NgfplacZ and EGS-Mtgfp were transcribed in vitro by T7 RNA 
Table 6: QPCR analyses of candidate target mRNAs of EGS-35

\begin{tabular}{|c|c|c|}
\hline Candidate target & Primer for QPCR & Inhibition level \\
\hline \multirow[t]{2}{*}{ NM 060051.2} & 5'-AGTCCGGTTTACTCCAAAGCAA-3' & $64 \%$ \\
\hline & 5'-CCATGAGGCTTTCCAAATGC-3' & \\
\hline \multirow[t]{2}{*}{ NM 076865.3} & 5'-TGGCGTTGCAGATAGAATAGGA-3' & $8 \%$ \\
\hline & 5'-GCCGAAAGCGACATAACCA-3' & \\
\hline \multirow[t]{2}{*}{ NM 062956.2} & 5'-CACCAGTAACCCAACAACTCCTAAA-3' & $6 \pm 5 \%$ \\
\hline & 5'-AAGGAGAATGCGACTGGGAAG-3' & \\
\hline \multirow[t]{2}{*}{ NM 066665.3} & 5'-TTGAGGCGAAATGCTTGTCA-3' & $7 \%$ \\
\hline & 5'-TGATGGCAAAATCGATGCA-3' & \\
\hline \multirow[t]{2}{*}{ NM 001029738.1} & 5'-TCGGAAACCAGGCAAACAAC-3' & $5 \%$ \\
\hline & 5'-GGTCATTGTGTGCCATTTCCTT-3' & \\
\hline \multirow[t]{2}{*}{ NM 072205.2} & 5'-TTGGTTAGAAGCGAAGTGAGTGA-3' & $9 \%$ \\
\hline & 5'-AAGGGAGGAGGAAATCAAGAGG-3' & \\
\hline \multirow{2}{*}{ NM 061028.1} & 5'-AGAGCACACGGCACATAGGA-3' & $5 \pm 5 \%$ \\
\hline & 5'-CTTGTTCGGGTCTGGGTTG-3' & \\
\hline \multirow[t]{2}{*}{ NM 015227.4} & 5'-GCACCTCAGTCTCAACATTTTCTTT-3' & $7 \%$ \\
\hline & 5'-TCACACGCCTTCTCTTGGTCT-3' & \\
\hline \multirow[t]{2}{*}{ NM 001047396.2} & 5'-GCTCCGATTCAAGTCATGTGG-3' & $7 \pm 5 \%$ \\
\hline & 5'-GCAAGCCGAAGAGGTGATGT-3' & \\
\hline \multirow[t]{2}{*}{ NM 001047395.1} & 5'-AGGAACACCAATGGTCACAATG-3' & $7 \%$ \\
\hline & 5'-GGAACTCCGAGAGCGTAAAGCT-3' & \\
\hline \multirow[t]{2}{*}{ NM 074332.2} & 5'-TCGTTCTGTCACGGGGAAC-3' & $5 \pm 6 \%$ \\
\hline & 5'-CTTCGCATCTTTTCCACCAAC-3' & \\
\hline \multirow{2}{*}{ NM 068962.3} & 5'-CATCGTCATCTAGTCTCCCAGTGT-3' & $8 \%$ \\
\hline & 5'-TTACTTCGTTTGGTTGGTGGTG-3' & \\
\hline
\end{tabular}

The accession number refers to the GenBank database. The values shown are means derived from triplicate experiments, and values for the standard deviation that were less than $5 \%$ are not shown.

polymerase (Epicentre) using purified PCR products of EGS-Ngfp-IVTT and EGS-Mtgfp-IVTT, respectively, as templates.

\section{Preparations of EGS-Ngfp-lacZ-D, EGS-Mtgfp-D, EGS-35- $D$ and EGS-83-D}

EGS-Ngfp-lacZ-D, EGS-Mtgfp-D, EGS-35-D and EGS-83D were derived from EGS-Ngfp-lacZ, EGS-Mtgfp, EGS-35 and EGS-83, respectively, and contained point mutations (5'-TTC-3' $\rightarrow$ AAG) at the three highly conserved positions in the "T-loop" of these EGSs. These nucleotides are found in most of the known natural tRNA sequences[49] and are thought to be important for the interactions between the tRNA domains and human RNase P[3]. Previous studies have shown that EGSs with these mutations prevented RNase P recognition and exhibited little activity in directing RNase-P-mediated cleavage[19,50,51]. EGS-NgfplacZ-D, EGS-Mtgfp-D, EGS-35-D and EGS-83-D were constructed according to the same strategy as described above. For full details, see additional files 7, 8, 9, 10, 11, 12, 13, 14,15 .

\section{Validation of effectiveness of EGS-Ngfp-lacZ and EGS- Mtgfp}

The purified EGSs were dissolved in $400 \mu$ l soaking buffer (10.9 $\mathrm{mM} \mathrm{Na}_{2} \mathrm{HPO}_{4}, 5.5 \mathrm{mM} \mathrm{KH}{ }_{2} \mathrm{PO}_{4}, 2.1 \mathrm{mM} \mathrm{NaCl}, 4.7$ $\mathrm{mM} \mathrm{NH}{ }_{4} \mathrm{Cl}, 6 \mathrm{mM}$ spermidine, and $0.1 \%$ gelatin)[34].
The final RNA concentration varied from 6 to $10 \mathrm{mg} / \mathrm{ml}$. Synchronous cultures of C. elegans strain PD4251 (containing 400 L1 larvae, 400 L2 larvae, 400 L3 larvae and 400 L4 larvae) in volumes of $400 \mu \mathrm{l} 0.25 \times$ M9 solution were added to EGS solution and shaken at $20^{\circ} \mathrm{C}$ for 24 hours. The treated worms underwent the following analyses: GFP fluorescence of PD4251 worms was imaged by microscope; to locate the nuclei, and worms were stained with Hoechst 33258 (sigma) according to standard protocol. Total RNA was prepared as described in the "Experimental Procedures and Protocols for Total RNA Isolation" developed and provided by Stuart Kim's laboratory. Primers for quantitative real-time PCR (QPCR) were: $e f t-2$ (eft2-QPCR-F and eft-2-QPCR-R) and GFP (GFP-QPCR-F and GFP-QPCR-R). QPCR was performed using PrimeScript ${ }^{\mathrm{TM}}$ RT reagent kit and PrimeScript ${ }^{\circledR}$ Premix Ex Taq ${ }^{\mathrm{TM}}$ kit (TAKARA) according to the manufacturer's instructions. Expression level of GFP mRNA was normalized to the mRNA eft-2 expression level. Protein was prepared according to the "Protocol of Protein prep from C. elegans and Western Analysis" provided by the Pasquinelli laboratory. Western-blot analysis was performed using the following antibodies: actin (I-19)(SANTA CRUZ sc-1616), GFP (B2) (SANTA CRUZ sc-9996), bovine anti-mouse IgG-AP (SANTA CRUZ sc-2373), and donkey anti-goat IgG-AP (SANTA CRUZ sc-2022). The films were imaged using the UVP gel imaging analytical system (Upland, GDS-8000) 
Table 7: Primer pairs for QPCR analysis candidate target mRNAs of EGS-83

\begin{tabular}{|c|c|c|}
\hline Candidate target & Primer for QPCR & Inhibition level \\
\hline \multirow[t]{2}{*}{ NM 066277.3} & 5'-AATCGAAAGCTCCGTTATCCAC-3' & $72 \%$ \\
\hline & 5'-TTCCCTCGGCTTCCAAAA-3' & \\
\hline \multirow[t]{2}{*}{ NM 058796.3} & 5'-TAAACGTGGCGGAGCTATCG-3' & $5 \%$ \\
\hline & 5'-CGTTCTCAATGCCCTTCCA-3' & \\
\hline \multirow[t]{2}{*}{ NM 066347.2} & 5'-AAAATCATTGGTCCCGTCATG-3' & $6 \%$ \\
\hline & 5'-CCAACCAAGAAGGGCATTCA-3' & \\
\hline \multirow[t]{2}{*}{ NM 062293.4} & 5'-AAGAGATGGATGTCTGGTAGTGGA-3' & $5 \pm 6 \%$ \\
\hline & 5'-GGAAGAGAGCATCGTTTTGGA-3' & \\
\hline \multirow[t]{2}{*}{ NM 070343.2} & 5'-AAGGACGGGAGGAACTGGA-3' & $6 \pm 5 \%$ \\
\hline & 5'-TTGGGAACGAGGGAACACTT-3' & \\
\hline \multirow{2}{*}{ NM 074278.2} & 5'-ACCTTCTTGTGCCAATATTTGGA-3' & $8 \%$ \\
\hline & 5'-TTGCCATGAAGTTTCCGAAAA-3' & \\
\hline \multirow[t]{2}{*}{ NM 059435.2} & 5'-TGGCGTCCGTTACCTTGAA-3' & $6 \%$ \\
\hline & 5'-GAATCAGCGGAGAATGCACAT-3' & \\
\hline \multirow{2}{*}{ NM 072012.1} & 5'-CCATTGGACATGGGAAAAACA-3' & $5 \%$ \\
\hline & 5'-TGGGATATTGGATTTTTGGGTCAA-3' & \\
\hline \multirow[t]{2}{*}{ NM 059793.2} & 5'-GGCACTTTTTGTTGCGATTGAA-3' & $6 \pm 5 \%$ \\
\hline & 5'-GGCTCTACAAGTTCCCAGCAAAT-3' & \\
\hline \multirow[t]{2}{*}{ NM 076117.3} & 5'-TGCAATTATGGTGCACTGATAACA-3' & $8 \%$ \\
\hline & 5'-TTGCGACATTTTCGAATCGA-3' & \\
\hline \multirow{2}{*}{ NM 059858.2} & 5'-GCGATGGTATTTTTGGCAGAA-3' & $6 \%$ \\
\hline & 5'-TTCTCCGTATCCGCACTTGAA-3' & \\
\hline \multirow[t]{2}{*}{ NM 061811.2} & 5'-TTTCAGAGTTTACCCGATGTTCAG-3' & $5 \%$ \\
\hline & 5'-CCGTATTTCCCGTAGTTTGAGG-3' & \\
\hline \multirow[t]{2}{*}{ NM 073812.2} & 5'-CCGAAGCGTCTGTATTAGTTGCT-3' & $5 \%$ \\
\hline & 5'-TTTGACTTTTGCGGTGGATG-3' & \\
\hline \multirow{2}{*}{ NM 076627.2} & 5'-GGGAGCAGTTGTGAGAGGATTT-3' & $7 \pm 5 \%$ \\
\hline & 5'-CCGCCTTCTCCGTCTTCTT-3' & \\
\hline \multirow[t]{2}{*}{ NM 069246.2} & 5'-GCTCTGGTCGCTACTCAATCAA-3' & $9 \%$ \\
\hline & 5'-ATTACTTCCTTGTGCCTCCATCTC-3' & \\
\hline \multirow[t]{2}{*}{ NM 061292.2} & 5'-CGCAAAACTCGGGCAAA-3' & $6 \%$ \\
\hline & 5'-GCCGTAGCCTCCATCAAAAC-3' & \\
\hline \multirow{2}{*}{ NM 063842.2} & 5'-TCGTCACATTTTCCGTTTCTCA-3' & $7 \%$ \\
\hline & 5'-GACCTGCTCCCCTGACAGTAGT-3' & \\
\hline NM 072852.1 & 5'-GGCTGAAACCAAGAACGAAAA-3' & $7 \%$ \\
\hline & 5'-TCGCAGAAGGAATGGAAGTG-3' & \\
\hline NM 066363.2 & 5'-TGAAAGCTGGCGAAGGACTT-3' & $5 \pm 5 \%$ \\
\hline & 5'-CAAGGGTTTCCAACGCAAAT-3' & \\
\hline NM 001028778.1 & 5'-CGAAGCGAACGGGATAATAGTG-3' & $6 \%$ \\
\hline & 5'-CGACTCATGTGCAAGTTATGTTCTT-3' & \\
\hline NM 171639.2 & 5'-CGAGGATGTTGCCATTCAGTT-3' & $7 \%$ \\
\hline & 5'-GAAGATTTGGGTTTTCACCATGA-3' & \\
\hline NM 171942.1 & 5'-TCAGATCACTCATGAACTCCATGA-3' & $5 \%$ \\
\hline & 5'-GAAGGGCGAAAATGAGAATGAA-3' & \\
\hline NM 171638.2 & 5'-CGGTGGAAGAGATGGATGAAG-3' & $6 \%$ \\
\hline & 5'-TTCGTGATTCGGTGGAACAA-3' & \\
\hline NM 001028115.1 & 5'-GCACAACTTTATCGCAACGATTA-3' & $6 \%$ \\
\hline & 5'-GCAAAGCTGGTGCAATTCTTC-3' & \\
\hline NM 001028116.1 & 5'-CTGCCTTTGCCGATGGTTA-3' & $6 \%$ \\
\hline & 5'-CTGGATAGTAGTAGGGCTCCGAAA-3' & \\
\hline NM 001028113.1 & 5'-CTGCCTTTGCCGATGGTTA-3' & $6 \%$ \\
\hline & 5'-CTGGATAGTAGTAGGGCTCCGAAA-3' & \\
\hline NM 001028114.1 & 5'-CTGCCTTTGCCGATGGTTA-3' & $6 \%$ \\
\hline & 5'-CTGGATAGTAGTAGGGCTCCGAAA-3' & \\
\hline NM 001027086.1 & 5'-GGAGCGCGTCAGAGTAAACG-3' & $7 \%$ \\
\hline & 5'-TTTCGAGACGGCCTTTGTTC-3' & \\
\hline NM 001027085.1 & 5'-GGAGCGCGTCAGAGTAAACG-3' & $7 \%$ \\
\hline & 5'-TTTCGAGACGGCCTTTGTTC-3' & \\
\hline NM 001029358.2 & 5'-ATGCATATTGAGCACGCAGAA-3' & $5 \%$ \\
\hline & 5'-CGGGCAGATGCAATTGTTT-3' & \\
\hline
\end{tabular}


Table 7: Primer pairs for QPCR analysis candidate target mRNAs of EGS-83 (Continued)

\begin{tabular}{lll}
\hline NM 001029357.3 & 5'-CGAGAGCGGCGAGTTGATAG-3' & $5 \%$ \\
NM 001029356.1 & 5'-ATACTGCATCCGAGCAACATGT-3' & \\
NM 001028371.1 & 5'-CGAGAGCGGCGAGTTGATAG-3' & $5 \%$ \\
NM 001013620.3 & 5'-ATACTGCATCCGAGCAACATGT-3' & $5 \%$ \\
& 5'-CCAAATGTTATGCCAGTCAAG-3' & $7 \%$ \\
& 5'-CAGACTTCATGACACATATTAAAGGACCA-3' & \\
\end{tabular}

The accession number refers to the GenBank database. The values shown are means derived from triplicate experiments, and values for the standard deviation that were less than $5 \%$ are not shown.

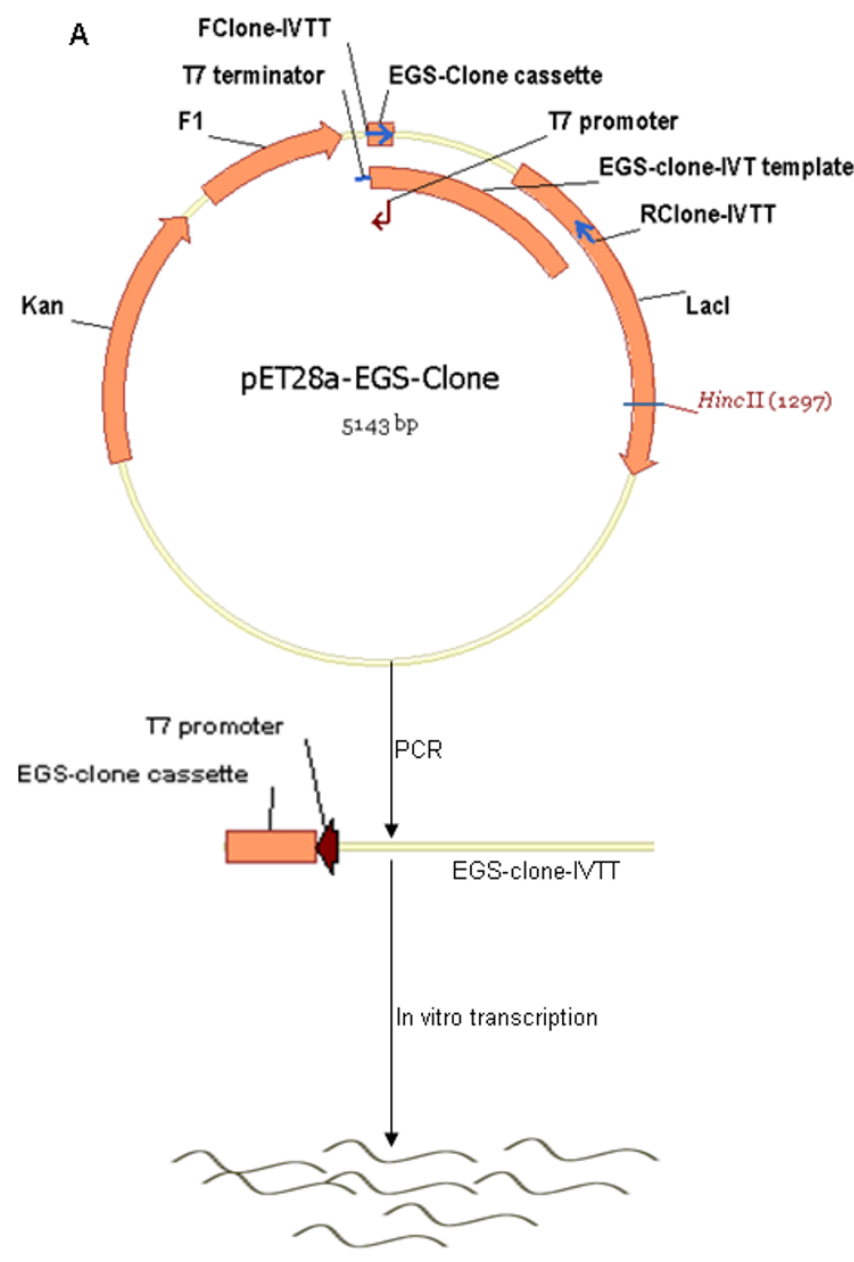

B

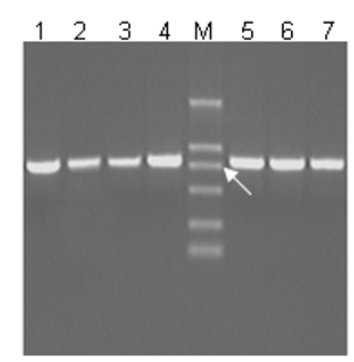

C

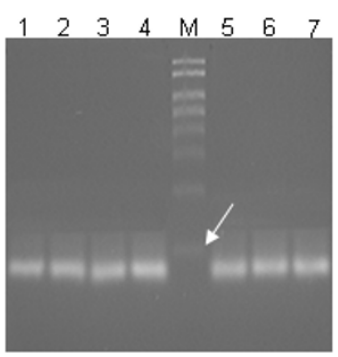

$\mathrm{D}$

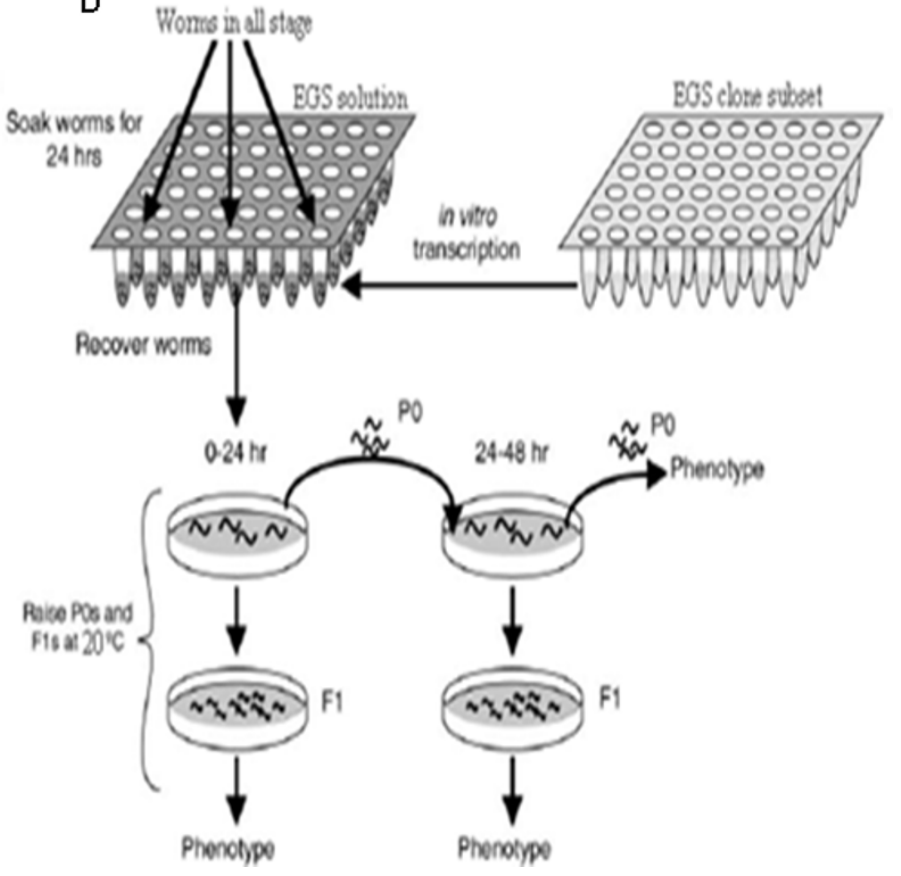

\section{Figure 8}

Reverse genetic screen of $C$. elegans based on EGS. (A) The flow chart of EGS-clone preparation. (B) The PCR product of the EGS clone IVTT (lanes I-7). The arrow indicates the 750-bp DNA band (lane M). (C) The transcription product of the EGS clone (lanes I-7). The arrow indicates the I00-bp RNA band (lane M). (D) Diagram of the phenotype screening procedure. 

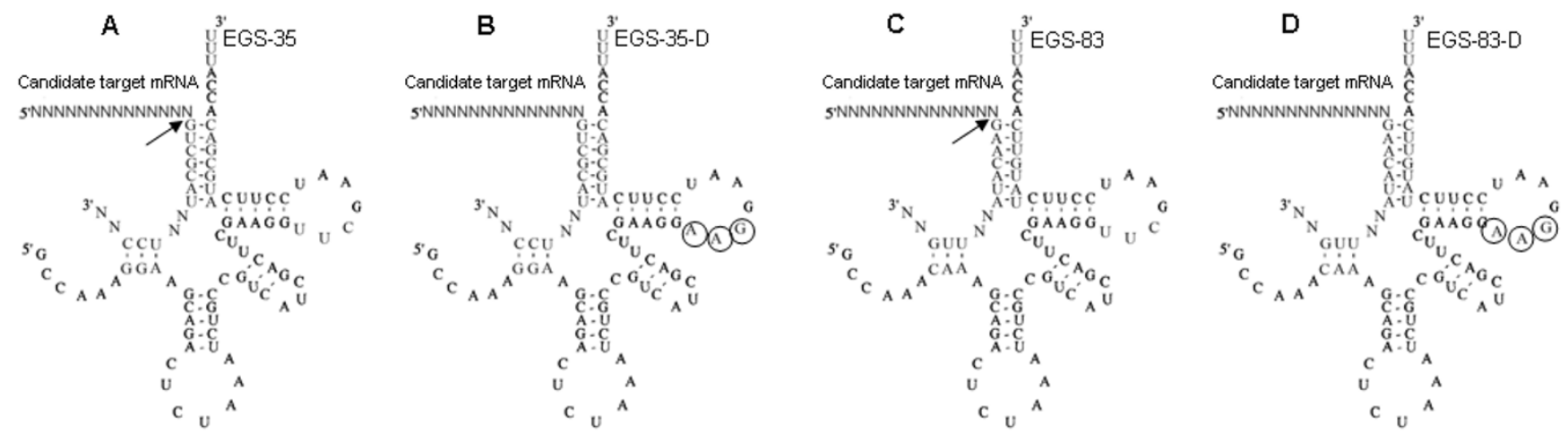

Figure 9

Complexes between candidate target mRNAs and EGS-35, EGS-35-D, EGS-83, EGS-83-D. (A, B) Complexes between a candidate target mRNA and EGS-35 (A) and EGS-35-D (B). The arrow indicates the RNase P cleavage site. EGS-35$\mathrm{D}$ was derived from EGS-35 by introducing base-substitution mutations at three positions (highlighted by circles) of the T-loop. (C, D) Complexes between a candidate target mRNA and EGS-83 (C) and EGS-83-D (D). The arrow indicates the RNase P cleavage site. EGS-83-D was derived from EGS-83 by introducing base-substitution mutations at three positions (highlighted by circles) of the T-loop.

and analyzed using Labworks software. Actin protein was used as an internal control.

\section{Construction of EGS library}

To construct pET28a-LEGS, which contains the EGS library cassette under control of the $\mathrm{T} 7$ promoter, the primer pair of FLEGSp and RLEGSp was designed using the NTI program and synthesized with random bases at certain positions and 5'-terminal phosphorylation modifications. pET28a-LEGSL was amplified by PCR with the primer pair of FEGSp and REGSp using pET28a as a template; the reaction conditions were $98^{\circ} \mathrm{C}$ for $60 \mathrm{~s}, 30$ cycles of $98^{\circ} \mathrm{C}$ for $5 \mathrm{~s}, 70^{\circ} \mathrm{C}$ for $15 \mathrm{~s}$ and $72^{\circ} \mathrm{C}$ for $90 \mathrm{~s}$, followed by $72^{\circ} \mathrm{C}$ for $10 \mathrm{~min}$, in $50-\mu$ l volumes with Phusion DNA Polymerase (NEB: F-530S). One microgram of the purified PCR product of pET28a-LEGSL was selfligated by T4 ligase (NEB) in a $1-\mathrm{ml}$ volume at $15^{\circ} \mathrm{C}$ for 16 hours. The ligation product was purified and transformed into DH5 $\alpha$ maximum efficiency competent cells (Invitrogen: 18258-012), and selection of bacterial clones was performed with $30 \mu \mathrm{g} / \mathrm{ml}$ kanamycin. Individual clones were selected at random for restriction enzyme digest with HincII and sequencing with the S-LEGS-F or SLEGS-R primers.

\section{Reverse genetic screen based on EGS}

PCR amplification of the EGS clone IVTT was performed with the primer pair of Fclone-IVTT and Rclone-IVTT using the pET28a-EGS clone as a template; the reaction conditions were: $98^{\circ} \mathrm{C}$ for $60 \mathrm{~s}, 30$ cycles of $98^{\circ} \mathrm{C}$ for $5 \mathrm{~s}$, $70^{\circ} \mathrm{C}$ for $15 \mathrm{~s}$ and $72^{\circ} \mathrm{C}$ for $15 \mathrm{~s}$, followed by $72^{\circ} \mathrm{C}$ for 10 min, in 50- $\mu$ l volume with Phusion DNA Polymerase (NEB: F-530S). The EGS clone was transcribed in vitro using T7 RNA polymerase (Epicentre) and the purified
PCR product of the EGS clone IVTT as a template. The purified EGS clone was dissolved in $4 \mu \mathrm{l}$ soaking buffer (10.9 $\mathrm{mM} \mathrm{Na}_{2} \mathrm{HPO}_{4}, 5.5 \mathrm{mM} \mathrm{KH} \mathrm{PO}_{4}, 2.1 \mathrm{mM} \mathrm{NaCl}, 4.7$ $\mathrm{mM} \mathrm{NH}_{4} \mathrm{Cl}, 6 \mathrm{mM}$ spermidine, and $0.1 \%$ gelatin)[34]. The final RNA concentration varied from 6 to $10 \mathrm{mg} / \mathrm{ml}$. Purified synchronous cultures of C. elegans strain N2 (containing 3 L1 larvae, 3 L2 larvae, 3 L3 larvae and 3 L4 larvae) in a volume of $4 \mu \mathrm{l} 0.25 \times \mathrm{M} 9$ solution were added to each EGS solution in 48-well PCR plates and shaken at $20^{\circ} \mathrm{C}$ for 24 hours. The worms were then transferred to new plates with food and phenotypes of both P0 worms and F1 progenies were recorded.

\section{Identification of target mRNA of EGS-35 and EGS-83}

All candidate target mRNAs of an EGS were identified by BLAST analysis of the target sequence (see Additional file 2 ). The expression levels of all candidate target mRNAs in worms treated with EGS-35 or EGS-83 were analyzed by QPCR as described above. Primers for QPCR are listed in Tables 6, 7 and 8. Expression levels of candidate target mRNA were normalized to the expression level of the mRNA eft-2.

\section{Authors' contributions}

QY validated EGS technology in C. elegans, generated the EGS library, performed the reverse genetic screen and wrote the first draft of the manuscript. RZ generated the EGS library, performed the reverse genetic screen and participated in writing the manuscript. CY performed the reverse genetic screen. BZ performed the Western-blot analysis. WZ and WM initiated the project, designed the EGS library and finalized writing the manuscript. All authors read and approved the final manuscript. 
Table 8: Primers used in this study

\begin{tabular}{|c|c|}
\hline Primer & Sequence \\
\hline FLEGSp & 5'-pTCGATGACGGCAGATTTAGAGTCTGCTNNNTTTGGCTATAGTGAGTCGTATTAATTTCG-3' \\
\hline RLEGSP & 5'-pCTTCGAAGGTTCGAATCCTTCNNNNNNNACCATTTTAGCATAACCCCTTGGGGCCTCT-3' \\
\hline FEGSp-Ngfp-lacZ & 5'p-TCGATGACGGCAGATTTAGAGTCTGCTTTCTTTGGCTATAGTGAGTCGTATTAATTTCG-3' \\
\hline REGSp-Ngfp-lacZ & 5'p-CTTCGAAGGTTCGAATCCTTCTTTAAATACCATTTTAAGCATAACCCCTTGGGGCCTCT-3' \\
\hline FEGSp-Mtgfp & 5'p-TCGATGACGGCAGATTTAGAGTCTGCTATCTTTGGCTATAGTGAGTCGTATTAATTTCG-3' \\
\hline REGSp-Mtgfp & 5'P-CTTCGAAGGTTCGAATCCTTCTATTAACACCATTTTAAGCATAACCCCTTGGGGCCTCT-3' \\
\hline FEGSp-Ngfp-lacZ-D & 5'P-TCGATGACGGCAGATTTAGAGTCTGCTTTCTTTGGCTATAGTGAGTCGTATTAATTTCG-3' \\
\hline REGSp-Ngfp-lacZ-D & 5'P-CTTCGAAGGAAGGAATCCTTCTTTAAATACCATTTTAGCATAACCCCTTGGGGCCTCT-3' \\
\hline FEGSp-Mtgfp-D & 5'p-TCGATGACGGCAGATTTAGAGTCTGCTATCTTTGGCTATAGTGAGTCGTATTAATTTCG-3' \\
\hline REGSp-Mtgfp-D & 5'p-CTTCGAAGGAAGGAATCCTTCTATTAACACCATTTTAGCATAACCCCTTGGGGCCTCT-3' \\
\hline FLEGSp-35-D & 5'-pTCGATGACGGCAGATTTAGAGTCTGCTTCCTTTGGCTATAGTGAGTCGTATTAATTTCG-3' \\
\hline RLEGSp-35-D & 5'-pCTTCGAAGGAAGGAATCCTTCATGCGACACCATTTTAAGCATAACCCCTTGGGGCCTCT-3' \\
\hline FLEGSp-83-D & 5'-pTCGATGACGGCAGATTTAGAGTCTGCTTTGTTTGGCTATAGTGAGTCGTATTAATTTCG-3' \\
\hline RLEGSp-83-D & 5'-pCTTCGAAGGAAGGAATCCTTCTATGTTCACCATTTTAGCATAACCCCTTGGGGCCTCT-3' \\
\hline Fclone-IVTT & 5'-AAATGGTNNNNNNNGAAG-3' \\
\hline Rclone -IVTT & 5'-AGATTGTGCACCGCCGCT-3' \\
\hline FNgfp-lacZ-IVTT & 5'-AAATGGTATTTAAAGAAGGA-3' \\
\hline RNgfp-lacZ-IVTT & 5'-AGATTGTGCACCGCCGCT-3' \\
\hline FMtgfp-IVTT & 5'-AAATGGTGTTAATAGAAGGA-3' \\
\hline RMtgfp-IVTT & 5'-AGATTGTGCACCGCCGCT-3' \\
\hline F35-IVTT & 5'-AAATGGTGTCGCATGAAG-3' \\
\hline R35 -IVTT & 5'-AGATTGTGCACCGCCGCT-3' \\
\hline F83-IVTT & 5'-AAATGGTGAACATAGAAG-3' \\
\hline R83 -IVTT & 5'-AGATTGTGCACCGCCGCT-3' \\
\hline eft-2-QPCR-F & 5'-GACGAGAAGGATTTGGAAGGAA-3' \\
\hline eft-2-QPCR-R & 5'-ACTGGGGATGGAAGATGGAA-3' \\
\hline GFP-QPCR-F & 5'-TGGAGTTGTCCCAATTCTTGTT-3' \\
\hline GFP-QPCR-R & 5'-GCATCACCTTCACCCTCTCC-3' \\
\hline S-EGS-F & 5'-TTAGAGCTTGACGGGGAAAG-3' \\
\hline S-EGS-R & 5'-CCTGCCACCATACCCACGCC-3' \\
\hline
\end{tabular}

The "p" in the "sequence" column represents the modification by phosphorylation. Fclone-IVTT is the outline of the corresponding primer used in the specific experiment. Base-substitution mutations at three positions of the T-loop are indicated by bold text. 


\section{Additional material}

\section{Additional File 1}

HincII digestion pattern. The HincII digestion products of the pET28aEGS clone (lane 1) containing two or three HincII sites, the pET28a-EGS clones (lanes 2-6) containing one HincII site, and DET28a (lane V). The arrow indicates the 5-kb DNA band (lane M).

Click here for file

[http://www.biomedcentral.com/content/supplementary/14726750-9-47-S1.tiff]

\section{Additional File 2}

All candidate target mRNAs of an EGS were identified by BLAST analysis of the target sequence. The NCBI-BLAST web interface.

Click here for file

[http://www.biomedcentral.com/content/supplementary/14726750-9-47-S2.tiff]

\section{Additional File 3}

Demonstration of primer pair. (A) The primer pair of FEGSp-Ngfp-lacZ and REGSp-Ngfp-lacZ. The partially randomized oligonucleotides of FEGSp-Ngfp-lacZ and REGSp-Ngfp-lacZ were composed of two parts. One was used to amplify pET28a-D, which is equal to pET28a but without the fragment between the T7 terminator and T7 promoter. The other was used to amplify the EGS-Ngfp-lacZ cassette. (B) The primer pair of FEGSp-Mtgfp and REGSp-Mtgfp. The partially randomized oligonucleotides of FEGSp-Mtgfp and REGSp-Mtgfp were composed of two parts. One was used to amplify pET28a-D; the other was used to amplify EGSMtgfp cassette.

Click here for file

[http://www.biomedcentral.com/content/supplementary/14726750-9-47-S3.tiff]

\section{Additional File 4}

Construction of pET28a-EGS-Ngfp-lacZ. (A) Flow chart showing construction of pET28a-EGS-Ngfp-lacZ. (B) The PCR product of pET28aEGS-Ngfp-lacZL (lane 1). The arrow indicates the 5-kb DNA band (lane $M)$.

Click here for file

[http://www.biomedcentral.com/content/supplementary/14726750-9-47-S4.tiff]

\section{Additional File 5}

Construction of pET28a-EGS-Mtgfp. (A) Flow chart showing pET28aEGS-Mtgfp construction. (B) The PCR product of pET28a-EGS-MtgfpL (lane 1). The arrow indicates the 5- $k b$ DNA band (lane M).

Click here for file

[http://www.biomedcentral.com/content/supplementary/14726750-9-47-S5.tiff]

\section{Additional File 6}

Preparations of EGS-Ngfp-lacZ and EGS-Mtgfp. (A) Flow chart showing preparation of EGS-Ngfp-lacZ. (B) Flow chart showing preparation of EGS-Mtgfp. (C) The PCR products of IVTT-EGS-Ngfp-lacZ (lane 1) and IVTT-EGS-Mtgfp (lane 2). The arrow indicates the 750-bp DNA band (lane M). (D) The transcription products of EGS-Ngfp-lacZ (lane 1) and EGS-Mtgfp (lane2). The arrow indicates the 100-bp RNA band (lane $M)$.

Click here for file

[http://www.biomedcentral.com/content/supplementary/14726750-9-47-S6.tiff]

\section{Additional File 7}

Demonstration of primer pair. (A) The primer pair of FEGSp-NgfplacZ-D and REGSp-Ngfp-lacZ-D. The partially randomized oligonucleotides of FEGSp-Ngfp-lacZ-D and REGSp-Ngfp-lacZ-D were composed of two parts. One was used to amplify pET28a-D, which is equal to $p E T 28$ a but without the fragment between the T7 terminator and T7 promoter. The other was used to amplify the EGS-Ngfp-lacZ-D cassette. (B) The primer pair of FEGSp-Mtgfp-D and REGSp-Mtgfp-D. The partially randomized oligonucleotides of FEGSp-Mtgfp-D and REGSp-Mtgfp-D were composed of two parts. One was used to amplify pET28a-D; the other was used to amplify EGS-Mtgfp-D cassette.

Click here for file

[http://www.biomedcentral.com/content/supplementary/14726750-9-47-S7.tiff]

\section{Additional File 8}

Demonstration of primer pair. (A) The primer pair of FEGSp-35-D and REGSp-35-D. The partially randomized oligonucleotides of FEGSp-35-D and REGSp-35-D were composed of two parts. One was used to amplify pET28a-D, which is equal to pET28a but without the fragment between the T7 terminator and T7 promoter. The other was used to amplify the EGS-35-D cassette. (B) The primer pair of FEGSp-83-D and REGSp-83$D$. The partially randomized oligonucleotides of FEGSp-83-D and REGSp-83-D were composed of two parts. One was used to amplify pET28a-D; the other was used to amplify the EGS-83-D cassette. Click here for file

[http://www.biomedcentral.com/content/supplementary/14726750-9-47-S8.tiff]

\section{Additional File 9}

Construction of pET28a-EGS-Ngfp-lacZ-D. (A) Flow chart showing construction of pET28a-EGS-Ngfp-lacZ-D. (B) The PCR product of pET28a-EGS-Ngfp-lacZ-DL (lane 1). The arrow indicates the 5-kb DNA band (lane M).

Click here for file

[http://www.biomedcentral.com/content/supplementary/14726750-9-47-S9.tiff]

\section{Additional File 10}

Construction of pET28a-EGS-Mtgfp-D. (A) Flow chart showing construction pET28a-EGS-Mtgfp-D. (B) The PCR product of pET28a-EGS$M t g f p-D L$ (lane 1). The arrow indicates the 5- $k b$ DNA band (lane M). Click here for file

[http://www.biomedcentral.com/content/supplementary/14726750-9-47-S10.tiff]

\section{Additional File 11}

Preparations of EGS-Ngfp-lacZ-D and EGS-Mtgfp-D. (A) Flow chart showing preparation of EGS-Ngfp-lacZ-D. (B) Flow chart showing preparation of EGS-Mtgfp-D. (C) The PCR products of IVTT-EGS-Ngfp-lacZ$D$ (lane 1) and IVTT-EGS-Mtgfp-D (lane 2). The arrow indicates the 750-bp DNA band (lane M). (D) The transcription products of EGSNgfp-lacZ-D (lane 1) and EGS-Mtgfp-D (lane2). The arrow indicates the 100-bp RNA band (lane M).

Click here for file

[http://www.biomedcentral.com/content/supplementary/14726750-9-47-S11.tiff] 


\section{Additional File 12 \\ Preparations of EGS-35 and EGS-83. (A) Flow chart showing prepara- tion of EGS-35. (B) Flow chart showing preparation of EGS-83. (C) The PCR products of IVTT-EGS-35 (lane 1) and IVTT-83 (lane 2). The arrow indicates the 750-bp DNA band (lane M). (D) The transcription products of EGS-35 (lane 1) and EGS-83 (lane 2). The arrow indicates the 100-bp RNA band (lane M). \\ Click here for file \\ [http://www.biomedcentral.com/content/supplementary/1472- 6750-9-47-S12.tiff]}

\section{Additional File 13}

Construction of pET28a-EGS-35-D. (A) Flow chart showing construction of $p E T 28 a-E G S-35-D$. (B) The PCR product of pET28a-EGS-35-DL (lane 1). The arrow indicates the 5-kb DNA band (lane $M$ ).

Click here for file

[http://www.biomedcentral.com/content/supplementary/14726750-9-47-S13.tiff]

\section{Additional File 14}

Construction of pET28a-EGS-83-D. (A) Flow chart showing construction of pET28a-EGS-83-D. (B) The PCR product of pET28a-EGS-83-DL (lane 1). The arrow indicates the 5- $k b$ DNA band (lane $M$ ).

Click here for file

[http://www.biomedcentral.com/content/supplementary/14726750-9-47-S14.tiff]

\section{Additional File 15}

Preparations of EGS-35-D and EGS-83-D. (A) Flow chart showing preparation of EGS-35Z-D. (B) Flow chart showing preparation of EGS83-D. (C) The PCR products of IVTT-EGS-35-D (lane 1) and IVTTEGS-83-D (lane 2). The arrow indicates the 750-bp DNA band (lane $M)$. (D) The transcription products of EGS-35-D (lane 1) and EGS-83$D$ (lane 2). The arrow indicates the 100-bp RNA band (lane M). Click here for file

[http://www.biomedcentral.com/content/supplementary/14726750-9-47-S15.tiff]

\section{Acknowledgements}

Nematode strains used in this work were provided by the Caenorhabditis Genetics Center, which is funded by the NIH National Center for Research Resources (NCRR). This work was funded by Science Project of the Key Lab of Guangdong province and the International Collaboration Project of Guangzhou City. We are grateful for scientific guidance on EGS library construction from Dr Sidney Altman, Professor in the Department of Cell, Molecular and Developmental Biology, Yale University.

\section{References}

I. Frank DN, Pace NR: Ribonuclease P: unity and diversity in a tRNA processing ribozyme. Annu Rev Biochem 1998, 67:153-180.

2. Trang P, Kim K, Liu F: Developing RNase $\mathbf{P}$ ribozymes for genetargeting and antiviral therapy. Cell Microbiol 2004, 6:499-508.

3. Altman S, Kirsebom LA: Ribonuclease P: Structure and Catalysis. In The RNA World. University of Utah, Salt Lake City; University of Colorado, Boulder; University of Utah, Salt Lake City) Volume Chapter 6.I. Third edition. Edited by: Raymond F Gesteland, Thomas R Cech, John F Atkins. Cold Spring Harbor Lab. Press, Plainview, NY; 2006.

4. Gopalan V, Vioque A, Altman S: RNase P: variations and uses. J Biol Chem 2002, 277:6759-6762.

5. Walker SC, Engelke DR: Ribonuclease P: the evolution of an ancient RNA enzyme. Crit Rev Biochem Mol Biol 2006, 41:77-102.
6. Li Y, Guerrier-Takada C, Altman S: Targeted cleavage of mRNA in vitro by $\mathbf{R N a s e} \mathbf{P}$ from Escherichia coli. Proc Natl Acad Sci USA 1992, 89:3185-3189.

7. Forster AC, Altman S: External guide sequences for an RNA enzyme. Science 1990, 249:783-786.

8. Yuan Y, Hwang ES, Altman S: Targeted cleavage of mRNA by human RNase P. Proc Natl Acad Sci USA 1992, 89:8006-80I0.

9. McKinney J, Guerrier-Takada C, Wesolowski D, Altman S: Inhibition of Escherichia coli viability by external guide sequences complementary to two essential genes. Proc Natl Acad Sci USA 200I, 98:6605-66I0.

10. Li Y, Altman S: Cleavage by RNase $\mathbf{P}$ of gene $\mathbf{N}$ mRNA reduces bacteriophage lambda burst size. Nucleic Acids Res 1996, 24:835-842.

II. Guerrier-Takada C, Li Y, Altman S: Artificial regulation of gene expression in Escherichia coli by RNase P. Proc Natl Acad Sci USA 1995, 92:111115-111119.

12. Guerrier-Takada C, Salavati R, Altman S: Phenotypic conversion of drug-resistant bacteria to drug sensitivity. Proc Natl Acad Sci USA 1997, 94:8468-8472.

13. Yang YH, Li H, Zhou T, Kim K, Liu F: Engineered external guide sequences are highly effective in inducing $R$ Nase $P$ for inhibition of gene expression and replication of human cytomegalovirus. Nucleic Acids Res 2006, 34:575-583.

14. Kovrigina E, Wesolowski D, Altman S: Coordinate inhibition of expression of several genes for protein subunits of human nuclear RNase P. Proc Natl Acad Sci USA 2003, 100:1598-1602.

15. Kovrigina E, Yang L, Pfund E, Altman S: Regulated expression of functional external guide sequences in mammalian cells using a U6 RNA polymerase III promoter. RNA 2005, I I:I588-1595.

16. Plehn-Dujowich D, Altman S: Effective inhibition of influenza virus production in cultured cells by external guide sequences and ribonuclease P. Proc Natl Acad Sci USA 1998, 95:7327-7332.

17. Li H, Trang P, Kim K, Zhou T, Umamoto S, Liu F: Effective inhibition of human cytomegalovirus gene expression and growth by intracellular expression of external guide sequence RNA. RNA 2006, I 2:63-72.

18. Liu F, Altman S: Inhibition of viral gene expression by the catalytic RNA subunit of RNase P from Escherichia coli. Genes Dev 1995, 9:47|-480.

19. Yuan Y, Altman S: Selection of guide sequences that direct efficient cleavage of mRNA by human ribonuclease $\mathbf{P}$. Science 1994, 263:1269-1273.

20. Rangarajan S, Raj ML, Hernandez JM, Grotewold E, Gopalan V: RNase $P$ as a tool for disruption of gene expression in maize cells. Biochem J 2004, 380:6 I I-6I6.

21. Dykxhoorn DM, Novina CD, Sharp PA: Killing the messenger: short RNAs that silence gene expression. Nat Rev Mol Cell Biol 2003, 4:457-467.

22. Rossi Jj: Ribozymes, genomics and therapeutics. Chem Biol 1999, 6:R33-R37.

23. Stein CA, Cheng YC: Antisense oligonucleotides as therapeutic agents-is the bullet really magical? Science 1993, 26I: $1004-1012$.

24. Santoro SW, Joyce GF: A general purpose RNA-cleaving DNA enzyme. Proc Natl Acad Sci USA 1997, 94:4262-4266.

25. Wong-Staal F, Poeschla EM, Looney DJ: A controlled, Phase I clinical trial to evaluate the safety and effects in HIV-I infected humans of autologous lymphocytes transduced with a ribozyme that cleaves HIV-I RNA. Hum Gene Ther 1998, 9:2407-2425.

26. Scherer LJ, Rossi J]: Approaches for the sequence-specific knockdown of mRNA. Nat Biotechnol 2003, 2 I: | $457-1465$.

27. Hammond SM, Bernstein E, Beach D, Hannon GJ: An RNA-directed nuclease mediates post-transcriptional gene silencing in Drosophila cells. Nature 2000, 404:293-296.

28. Guerrier-Takada C, Altman S: Inactivation of gene expression using ribonuclease $\mathbf{P}$ and external guide sequences. Methods Enzymol 2000, 3 I 3:442-456.

29. Kim K, Liu F: Inhibition of gene expression in human cells using RNase P-derived ribozymes and external guide sequences. Biochim Biophys Acta 2007, 1769:603-6I2.

30. Fraser AG, Kamath RS, Zipperlen P, Martinez-Campos M, Sohrmann $M$, Ahringer J: Functional genomic analysis of $C$. elegans chro- 
mosome I by systematic RNA interference. Nature 2000, 408:325-330.

31. Gonczy P, Echeverri C, Oegema K, Coulson A, Jones SJ, Copley RR, Duperon J, Oegema J, Brehm M, Cassin E, et al.: Functional genomic analysis of cell division in C. elegans using RNAi of genes on chromosome III. Nature 2000, 408:33I-336.

32. Piano F, Schetter AJ, Mangone M, Stein L, Kemphues KJ: RNAi analysis of genes expressed in the ovary of Caenorhabditis elegans. Curr Biol 2000, 10:1619-1622.

33. Hanazawa $M$, Mochii $M$, Ueno $N$, Kohara $Y$, lino $Y$ : Use of cDNA subtraction and RNA interference screens in combination reveals genes required for germ-line development in Caenorhabditis elegans. Proc Natl Acad Sci USA 200I, 98:8686-869l.

34. Maeda I, Kohara Y, Yamamoto M, Sugimoto A: Large-scale analysis of gene function in Caenorhabditis elegans by high-throughput RNAi. Curr Biol 200I, I I: I7I-176.

35. Zipperlen P, Fraser AG, Kamath RS, Martinez-Campos M, Ahringer J: Roles for 147 embryonic lethal genes on C.elegans chromosome I identified by RNA interference and video microscopy. EMBO J 200I, 20:3984-3992.

36. Ashrafi K, Chang FY, Watts JL, Fraser AG, Kamath RS, Ahringer J, Ruvkun G: Genome-wide RNAi analysis of Caenorhabditis elegans fat regulatory genes. Nature 2003, 42 I:268-272.

37. Kamath RS, Fraser AG, Dong $Y$, Poulin G, Durbin R, Gotta M, Kanapin A, Le BN, Moreno S, Sohrmann M, et al.: Systematic functional analysis of the Caenorhabditis elegans genome using RNAi. Nature 2003, 42I:23I-237.

38. Lee SS, Lee RY, Fraser AG, Kamath RS, Ahringer J, Ruvkun G: A systematic RNAi screen identifies a critical role for mitochondria in C. elegans longevity. Nat Genet 2003, 33:40-48.

39. Pothof J, van HG, Thijssen K, Kamath RS, Fraser AG, Ahringer J, Plasterk $\mathrm{RH}$, Tijsterman M: Identification of genes that protect the C. elegans genome against mutations by genome-wide RNAi. Genes Dev 2003, 17:443-448.

40. Simmer F, Moorman C, Linden AM van der, Kuijk E, Berghe PV van den, Kamath RS, Fraser AG, Ahringer J, Plasterk RH: Genome-wide RNAi of C. elegans using the hypersensitive rrf-3 strain reveals novel gene functions. PLoS Biol 2003, I:EI2.

41. Vastenhouw NL, Fischer SE, Robert VJ, Thijssen KL, Fraser AG, Kamath RS, Ahringer J, Plasterk RH: A genome-wide screen identifies $\mathbf{2 7}$ genes involved in transposon silencing in $\mathrm{C}$. elegans. Curr Biol 2003, 13:13 | |-1316.

42. Rual JF, Ceron J, Koreth J, Hao T, Nicot AS, Hirozane-Kishikawa T, Vandenhaute J, Orkin SH, Hill DE, van den HS, et al.: Toward improving Caenorhabditis elegans phenome mapping with an ORFeome-based RNAi library. Genome Res 2004, 14:2162-2168.

43. Dillin A, Hsu AL, rantes-Oliveira N, Lehrer-Graiwer J, Hsin H, Fraser AG, Kamath RS, Ahringer J, Kenyon C: Rates of behavior and aging specified by mitochondrial function during development. Science 2002, 298:2398-240I.

44. Piano F, Schetter A], Morton DG, Gunsalus KC, Reinke V, Kim SK, Kemphues KJ: Gene clustering based on RNAi phenotypes of ovary-enriched genes in C. elegans. Curr Biol 2002, | 2:1959-1964.

45. Fire A, Xu S, Montgomery MK, Kostas SA, Driver SE, Mello CC: Potent and specific genetic interference by double-stranded RNA in Caenorhabditis elegans. Nature 1998, 39 I:806-8I I.

46. Zuker M: Mfold web server for nucleic acid folding and hybridization prediction. Nucleic Acids Res 2003, 31:3406-3415.

47. McClain WH, Guerrier-Takada C, Altman S: Model substrates for an RNA enzyme. Science 1987, 238:527-530.

48. Guerrier-Takada C, McClain WH, Altman S: Cleavage of tRNA precursors by the RNA subunit of $E$. coli ribonuclease $P$ (MI RNA) is influenced by 3 '-proximal CCA in the substrates. Cell 1984, 38:219-224

49. Sprinzl M, Dank N, Nock S, Schon A: Compilation of tRNA sequences and sequences of tRNA genes. Nucleic Acids Res I991, 19(Suppl):2|27-217I.

50. Zhu J, Trang P, Kim K, Zhou T, Deng H, Liu F: Effective inhibition of Rta expression and lytic replication of Kaposi's sarcomaassociated herpesvirus by human RNase P. Proc Natl Acad Sci USA 2004, 101:9073-9078.

5I. Zhou T, Kim J, Kilani AF, Kim K, Dunn W, Jo S, Nepomuceno E, Liu $F$ : In vitro selection of external guide sequences for directing
RNase P-mediated inhibition of viral gene expression. J Biol Chem 2002, 277:30II2-30I20.

52. Ma Y, Creanga A, Lum L, Beachy PA: Prevalence of off-target effects in Drosophila RNA interference screens. Nature 2006, 443:359-363.

53. Kulkarni MM, Booker M, Silver SJ, Friedman A, Hong P, Perrimon N, Mathey-Prevot B: Evidence of off-target effects associated with long dsRNAs in Drosophila melanogaster cell-based assays. Nat Methods 2006, 3:833-838.

54. Scacheri PC, Rozenblatt-Rosen O, Caplen NJ, Wolfsberg TG, Umayam L, Lee JC, Hughes CM, Shanmugam KS, Bhattacharjee A, Meyerson M, et al: Short interfering RNAs can induce unexpected and divergent changes in the levels of untargeted proteins in mammalian cells. Proc Natl Acad Sci USA 2004, I0I: I892-1897.

55. Kawa D, Wang J, Yuan Y, Liu F: Inhibition of viral gene expression by human ribonuclease $P$. RNA 1998, 4:1397-1406.

56. Theresa Stiernagle: Theresa Stiernagle. Maintenance of C.elegans. WormBook, ed. The C.elegans Research Community, WormBook, doi/l0.1895/wormbook.I.7.I. WormBook 2005 [http://www.wormbook.org]. The C.elegans Research Community, WormBook
Publish with Bio Med Central and every scientist can read your work free of charge

"BioMed Central will be the most significant development for disseminating the results of biomedical research in our lifetime. "

Sir Paul Nurse, Cancer Research UK

Your research papers will be:

- available free of charge to the entire biomedical community

- peer reviewed and published immediately upon acceptance

- cited in PubMed and archived on PubMed Central

- yours - you keep the copyright

Submit your manuscript here:

http://www.biomedcentral.com/info/publishing_adv.asp 